\title{
Los centros de acogida para víctimas de violencia de género en Galicia y Asturias, ¿modelos arquitectónicos de hogar?
}

\author{
Selina Ugarte-Fidalgo ${ }^{1}$ | María Carreiro-Otero ${ }^{2}$ | Cándido López-González ${ }^{3}$ \\ Recibido: 13-10-2020 | en su versión final: 12-02-2021
}

Resumen En la Inglaterra de los años 70 del siglo XX, se pusieron en marcha los primeros refugios para víctimas de violencia de género, impulsados por activistas y organizaciones feministas. Con el tiempo, se han incorporado como un imprescindible recurso habitacional a la política de lucha contra la violencia de género. Pese a ello, al menos hasta el momento, en España no se ha tenido en cuenta la adecuación de sus condiciones arquitectónicas al doble objetivo que han de satisfacer: proteger a las mujeres de sus agresores, por un lado, y prestarles apoyo para superar su lesiva situación por otro. Según esto, los centros deben proporcionar seguridad, así como bienestar físico y psicológico, aspectos que responden a unas características espaciales y formales que están por definir. El artículo propone determinarlas a partir de la hogaridad, término que liga las cualidades espaciales propias del hogar con indicadores arquitectónicos mensurables, independientes del programa, la organización, el enfoque conceptual y el tipo residencial del recurso. La aplicación de ese conjunto de indicadores constituye un método para la valoración, individual o comparada, de cualquier centro de acogida, al señalar los requerimientos espaciales y formales necesarios para la puesta en marcha del recurso habitacional. Para verificar su idoneidad se aplica a tres ejemplos que, ubicados en el ámbito territorial de las comunidades autónomas de Galicia y Asturias, representan las tres modalidades existentes de centros. Los resultados muestran la utilidad del método, sea como una herramienta para el diagnóstico de los centros existentes, sea como una guía para el proyecto arquitectónico, ex novo o de acondicionamiento.

Palabras clave: Recurso habitacional; red de acogida; bienestar físico; bienestar psicológico

Citación

Ugarte, S. et al. (2021). Los centros de acogida para víctimas de violencia de género en Galicia y Asturias, ¿modelos arquitectónicos de 'hogar'? ACE: Architecture, City and Environment, 16(46), 9703. DOI: http://dx.doi.org/10.5821/ace.16.46.9703

\section{The Shelters for Gender-Based Victims in Galicia and Asturias, Architectural Models of Home?}

Abstract

\begin{abstract}
In the 70 s of the 20th century, the first shelters for victims of gender-based violence were set up in England, promoted by activists and feminist organizations. Over the time, they have been incorporated as an essential residential facility into the policy to fight against gender-based violence. Despite this, at least so far, Spain has not taken into account the adaptation of their architectural conditions to the double objective that they have to fulfill: protecting women from their aggressors, on one hand, and to provide them with support to overcome their harmful situation, on the other. According to this, the facilities have to provide security, as well as physical and psychological wellbeing, aspects that respond to spatial and formal characteristics that are yet to be defined. The article proposes to determine them from the homeness, a term that link the proper spatial qualities of a home with measurable architectural indicators, independent of the programme, the organization, the conceptual approach, and the housing type of the facility. The application of this set of indicators constitutes a method for the assessment, individual or compared, of any shelter by pointing out the spatial and formal requirements that are necessary for the setting up of any housing facility. In order to verify their suitability, they are applied to three examples that, located within the territorial scopes of the autonomous communities of Galicia and Asturias, represent the three existing forms of the shelters. The results prove the usefulness of the method, either as a diagnostic tool for already existing facilities or as a guide for an architectural project, ex novo or fitting-out works.
\end{abstract}

Keywords: Housing facility; housing network; physical wellbeing; psychological wellbeing

${ }^{1}$ Arquitecta, Doctoranda del grupo GAUS, Universidade da Coruña (ORCID: 0000-0002-4870-1709); ${ }^{2}$ Doctora en Arquitectura, Docente e Investigadora, grupo GAUS, Universidade da Coruña (ORCID ID: 0000-0001-63517902, Scopus Author ID: 56536882500, Researcher ID: AAF-4714-2021); ${ }^{3}$ Doctor en Arquitectura, Docente e Investigador, grupo GAUS, Universidade da Coruña (ORCID ID: 0000-0003-3388-6859, Scopus ID: 56536630000, Researcher ID: AAF-4722-2021). Correo de contacto: s.ugarte@udc.es 


\section{Introducción}

La palabra ‘hogar' hace referencia al lugar donde se enciende el fuego para templar el espacio, haciéndolo acogedor. También se asocia a una experiencia multidimensional difícil de describir objetivamente (Pallasmaa, 1994), de tal modo que el hogar, como concepto, se construye añadiendo a la primaria imagen de protección y orden (Bachelard, 1998/1957) el propio bagaje cultural y psicológico. Cargado de significado emocional, en él se "producen relaciones sociales que se extienden más allá de las barreras físicas”1 (Tester, 2013, pág. 71)

Coloquialmente este vocablo, hogar, se identifica con vivienda y con casa -incluso se emplean como sinónimos- aunque cada uno de estos términos representa una faceta del habitar. La vivienda aporta la parte arquitectónica y el confort físico; la casa, la parte socioeconómica y el confort social; y el hogar, la parte cultural (Pinilla, 2005) y el confort psicológico (Lotito Catino, 2009; Gray, 2019). Sin embargo, determinadas situaciones, como la violencia de género, introducen desazón, rompiendo la ligazón entre persona y hogar. Una situación que puede afectar a cualquier mujer, independientemente de su edad, raza o estatus socioeconómico (López Díaz, 2019).

La violencia de género se reconoce como un problema estructural de difícil resolución. Recluido en el ámbito privado durante largo tiempo, una parte de la sociedad, aún a día de hoy espera que se resuelva en el entorno familiar. Políticamente tiende a abordarse como una cuestión híbrida, entre asistencial y de orden público, priorizando en exceso el enfoque policial (Portas Pérez, 2019).

El proceso de incorporación a la esfera de lo público comenzó en los años 70 del siglo XX, cuando se promovieron los centros de acogida para mujeres víctimas de maltrato. El primero de ellos, el Chiswick Women's Aid, se fundó en Londres en 1971, con el objetivo inicial de ofrecer "té, simpatía y un lugar seguro para quedarse"2 (Pizzey, 2011). Nacido de manera informal, su ejemplo se extendió por la comunidad internacional, forzando a las administraciones públicas a integrar el problema en la agenda social.

Transcurrido medio siglo desde entonces, los refugios -centros- para víctimas de violencia de género ${ }^{3}$ se han convertido en una importante herramienta para protegerlas de sus agresores; para ofrecerles la oportunidad de reconocerse y valorarse, de recuperar la dignidad, sin "enjaularlas" (Joshi, 2017, pág. 15). Qué menos, por tanto, que puedan sentirlos como un 'hogar', aun cuando los habiten de modo transitorio. De ahí que los centros deban incorporar las condiciones necesarias para serlo (Wagenaar, 2008).

Dichas condiciones emergen de la relación entre la arquitectura (Ugarte-Fidalgo et al., 2019), y el hecho psicológico-cultural del habitar, designada como hogaridad. Un concepto abstracto que se aborda desde la óptica estrictamente arquitectónica, ${ }^{4}$ ya que solo desde esta se podrá trasponer a la forma construida. Esta acción aúna la investigación arquitectónica (Carreiro y López, 2016) con la perspectiva de género (Bofill, 2005; Concejalía de Igualdad y Empleo, 2007), valiéndose de una serie de características espaciales, los indicadores. Para definirlos se recurrirá a la técnica proyectual, el

\footnotetext{
1 Traducción: Selina Ugarte-Fidalgo.

2 Traducción: Selina Ugarte-Fidalgo.

3 Aplicando la nomenclatura establecida en el Pacto de Estado contra la Violencia de Género de 2017, PEVG2017, se denominan 'recursos habitacionales', término que incluye todo tipo de alojamiento, desde los centros hasta las viviendas temporales.

${ }^{4}$ Se aplica el enfoque arquitectónico frente a otros dos posibles: el sociológico, y el urbanístico, La arquitectura y el urbanismo trabajan sobre el espacio físico, pero con distintas escalas y finalidades. Por su parte, la sociología, aunque estudia la relación espacio-habitante, difiere claramente de ambos en cuanto a método, herramientas y expresión.
}

ACE, 16 (46) CC BY-ND 3.0 ES | UPC Barcelona, España | Los centros de acogida para víctimas de violencia de género en Galicia y Asturias, ¿modelos arquitectónicos de hogar? DOI: http://dx.doi.org/10.5821/ace.16.46.9703 
análisis arquitectónico; así como al conocimiento de los centros, adquirido durante el desarrollo del proyecto TIP-CAVI $2,{ }^{5}$ sumado a la revisión bibliográfica plasmada en el "Estudio del Arte".

Una vez establecidos los indicadores, se aplicarán a tres centros de acogida para víctimas de violencia de género, CAVGe: la Casa de Acogida de Ferrol, el Centro de Emergencia de Vigo y la Casa Malva de Gijón (Carreiro-Otero et al., 2019). Casos de estudio que pueden tomarse como paradigmas de los recursos habitacionales en cuanto a enfoque conceptual, gestión, posición en la trama urbana, y características arquitectónicas.

La discusión surgida en este proceso nos permitirá determinar tanto la validez del concepto de hogaridad, como la pertinencia de los indicadores que la identifican. Además, establecerá su eficacia como una herramienta de trabajo, al servicio, bien del proyecto arquitectónico, o bien de la valoración de los CAVGe existentes.

\section{Estado del arte}

El interés en el bienestar psicológico ha dado lugar a la Teoría del Bienestar Psicológico de Ryff (Romero Carrasco, Brustad, y García Mas, 2007), desarrollada a partir de los años 80 del siglo XX. Carol Ryff (1989; 1995; 2017) vincula el equilibrio entre emociones positivas y negativas con el bienestar psicológico a través de seis dimensiones: el dominio del entorno, la autoaceptación, el sentido de la propia vida, la autonomía, las relaciones positivas con otras personas, y el crecimiento personal. Dimensiones condicionadas por el entorno físico, dada la relación entre el espacio, público y privado, y la confortabilidad física y psicológica de las personas.

En cuanto a la violencia de género y los recursos para combatirla, cabe reseñar que las administraciones competentes registran periódicamente su incidencia en informes de corte estadístico, fundamentalmente. En el caso de España están disponibles en la página web del Ministerio de Sanidad, en la del Instituto de las Mujeres de España, y en las correspondientes a las administraciones autonómicas y locales. A su vez, en el ámbito académico se investiga el tema considerando el tránsito de la violencia de género de un problema privado a uno normalizado (Ruffa, 1990; Bosch Fiol y Ferrer Pérez, 2000; Sullivan y Gillum, 2001); la taxonomía de los centros según su gestión (Dobash y Dobash, 1992); o su utilidad para la recuperación de las mujeres (Booth, Darke y Yeandle, 1998; Bennett, Riger, Schewe, Howard, y Wasco, 2004). También se analiza desde la óptica sociológica (Peña Cristiá, 2004), o particularizando en casos concretos (Rebollo Sánchez y Bravo Campanón, 2005; Merelas, 2013; Moriana Mateo 2014, 2015, y 2016; La Torre y Roig Forteza, 2011).

Ninguno de ellos tiene en cuenta la repercusión de la "arquitectura como herramienta terapéutica en el campo de la salud mental” (Becerra Verdugo, 2017, pág. 170). Y la lectura de los pocos realizados desde la esfera arquitectónica nos remiten a las palabras de Arenal (2019/1883: pág. 160), escritas hace más de un siglo: "Se dirá que en España también existen asociaciones bienhechoras; pero sobre que faltan para un gran número de objetos esenciales, las que hay, por reducidas proporciones o escasos medios, sirven más bien para indicar necesidad que para satisfacerla".

\footnotetext{
${ }^{5}$ El proyecto TIP-CAVI² fue desarrollado por Carreiro-Otero, López-González, Ugarte-Fidalgo y Vázquez-García a lo largo del año 2019, dentro de las acciones de investigación derivadas del PEVG2017. Se ha plasmado en un informe que da cuenta de la visita a diversos centros, las entrevistas no estructuradas con las responsables, el cartografiado de sus planos, la recopilación de la normativa estatal y autonómica, el estudio de las propuestas de otros países, entre ellos Holanda, Estados Unidos, o Austria, y la incorporación de los resultados -dieciséis proyectos de arquitectura- de un taller de Trabajo Fin de Máster que abordó el tema de un Centro de Acogida para Víctimas de Violencia de Género durante el curso académico 2017/18 en la Universidade da Coruña.
}

ACE, 16 (46) CC BY-ND 3.0 ES | UPC Barcelona, España | Los centros de acogida para víctimas de violencia de género en Galicia y Asturias, ¿modelos arquitectónicos de hogar? DOI: http://dx.doi.org/10.5821/ace.16.46.9703 
La escasa literatura que desde la disciplina arquitectónica aborda este tema confluye, entre otros objetivos, en el establecimiento de las cualidades arquitectónicas propias de estos centros. Los trabajos desarrollados por Refuerzo y Verderber (1993), el de Carreiro et al. (2019) y el de Donnelly (2020) desde diferentes contextos socioculturales -Estados Unidos, España y Australia respectivamente- nos servirán de referencia para definir los indicadores de hogaridad.

\section{Hogaridad e Indicadores arquitectónicos}

Los citados textos, el de Refuerzo y Verdeber, el de Donnelly y el de TIP-CAVI2 tratan de sistematizar los requerimientos de los CAVGe mediante guías o patrones arquitectónicos. Se aproximan a los aspectos globales del tema -el programa y las condiciones espaciales de un centro de acogida- para, seguidamente, determinar los correspondientes indicadores arquitectónicos. Aplican los tres un método análogo de trabajo: un proceso iterativo de análisis-síntesis, propio del área proyectual. También coinciden en la forma de recabar información -visitas a diversos centros- y en el tipo de datos recopilados, tanto de índole arquitectónica -programa, superficie, iluminación, estructura funcional...-, como estadística -encuestas y entrevistas, más o menos estructuradas, realizadas tanto a las usuarias como a las responsables de los centros.

En el primero, Refuerzo y Verderber (1993) estudian centros ubicados a lo largo y ancho de Estados Unidos. Ponen el foco en los aspectos funcionales, que clasifican en siete áreas: de acceso, de asesoramiento, de guardería, residencial común, residencial privada, de recepción y de tratamientos. Estas se definen a través de 16 indicadores distintos de un total de 22. En el segundo de ellos, Donnelly (2020) que se ciñe a los centros del área metropolitana de Sidney, Australia, fija ocho principios de diseño: accesibilidad, dignidad, enfoque en los niños, flexibilidad, privacidad, seguridad, sensación de hogar y sostenibilidad, con 25 indicadores diferenciados de un total de 32. Por su parte, el tercero, el proyecto de investigación TIP-CAVI2 (2019) acota el trabajo a la Comunidad de Galicia, planteando tres parámetros: arquitectónicos técnicos, arquitectónicos proyectuales y personales, con 11 indicadores. Los tres estudios manejan unas mismas cualidades espaciales, que se sintetizan en cuatro: seguridad, convivencia, intimidad, e interacción ambiental (Figura. 1). Aspectos que resultan coincidentes mediante una visión agregada de los tres, pese a la diferente nomenclatura y al alcance de cada uno (Figura 2).

Figura 1. Cualidades, características e indicadores de hogaridad

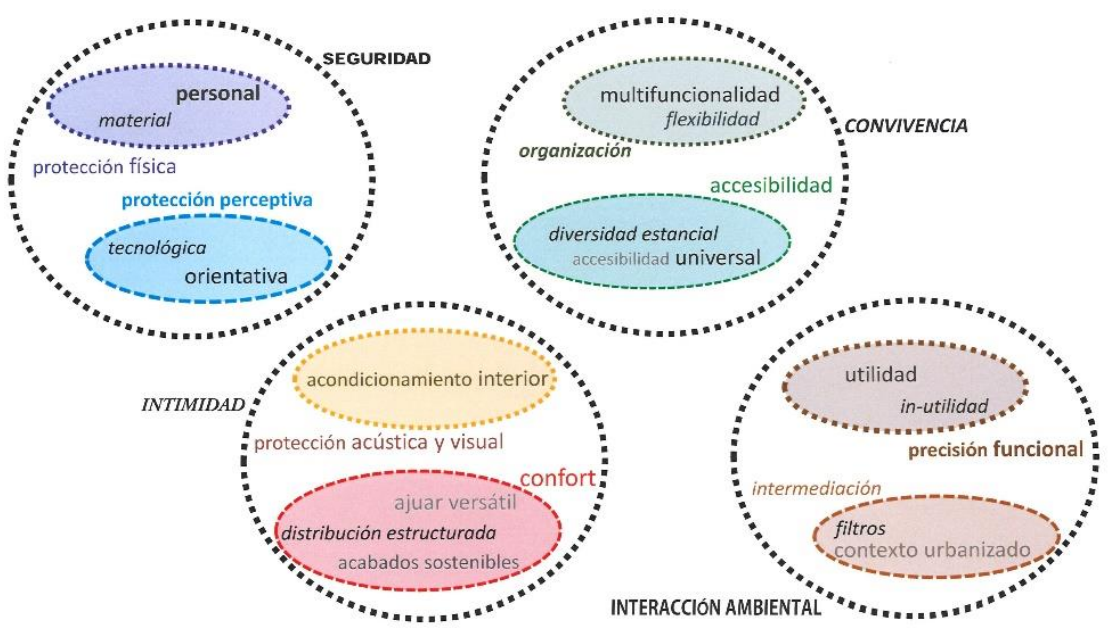

Fuente: Elaboración propia.

ACE, 16 (46) CC BY-ND 3.0 ES | UPC Barcelona, España | Los centros de acogida para víctimas de violencia de género en Galicia y Asturias, ¿modelos arquitectónicos de hogar? DOI: http://dx.doi.org/10.5821/ace.16.46.9703 
Estas cualidades constituyen la primera aproximación a la hogaridad, un requerimiento intrínseco a cualquier CAVGe que aspire a ofrecer refugio a las mujeres, y las impulse a reconstruir sus vidas (Bennett, Riger, Schewe, Howard, y Wasco, 2004). Equivalente a 'calidad de hogar', se plasma en un gradiente cuyos valores se determinan de manera indirecta (Wathen, Harris, Ford-Gilboe y Hansen, 2015), a través de indicadores -indicios-. No obstante, para pasar de hogaridad, a los 'indicios de hogaridad debe recurrirse a un segundo estrato, el de las características que intermedien entre la abstracción de las cualidades y la concreción de los indicadores. Como se aprecia en la Figura 1, en cada una de las cualidades señaladas se incluyen dos características que, a su vez incorporan las correspondientes series de indicadores.

Figura 2. Indicadores arquitectónicos aportados por Refuerzo y Verdeber, Donnelly, y el equipo de TIP-CAVI2, en relación con las cualidades arquitectónicas de hogaridad

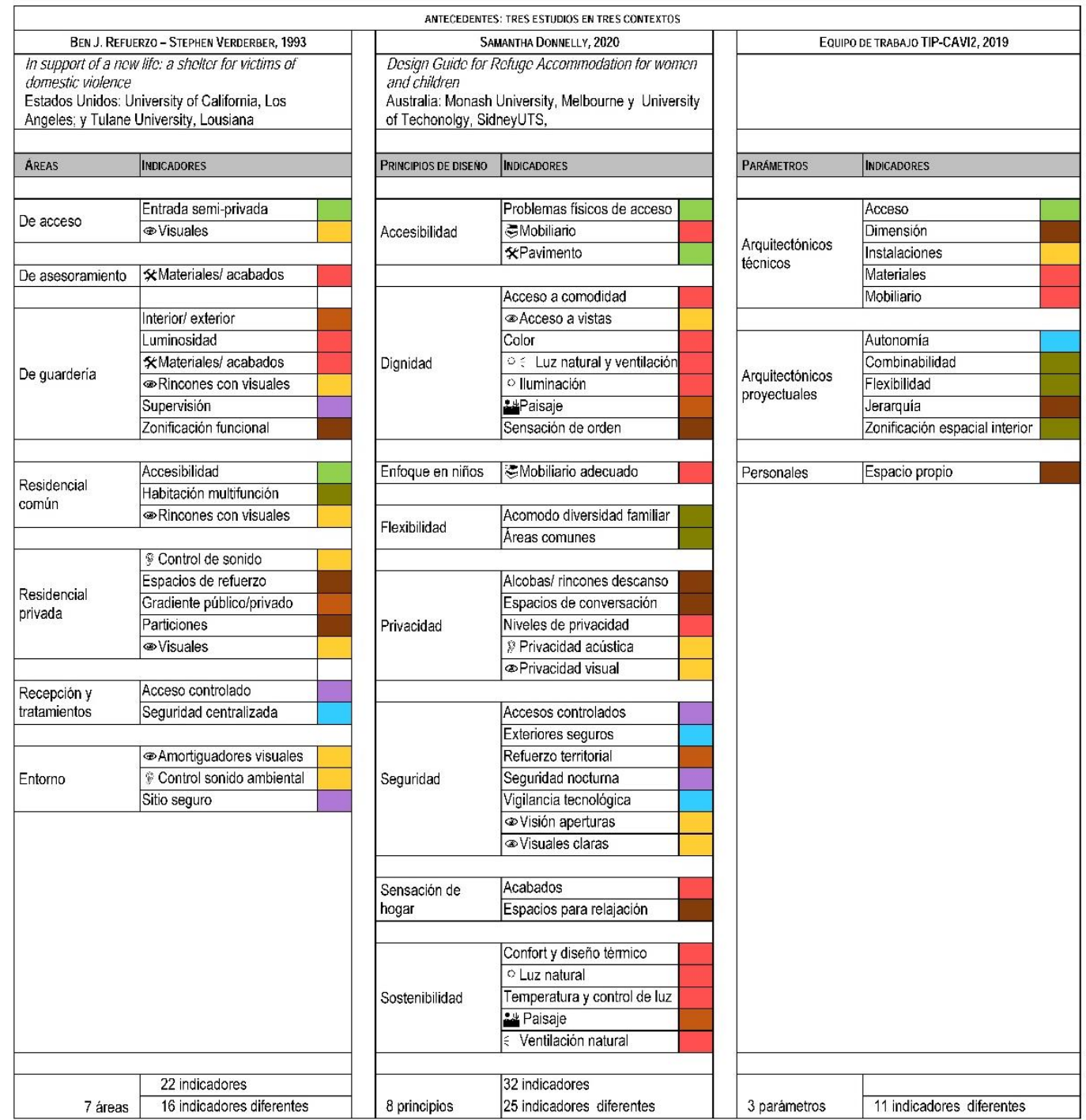

\begin{tabular}{|c|c|c|c|}
\hline SEGURIDAD & CONVIVENCIA & INTIMIDAD & INTERACCIÓN AMBIENTAL \\
\hline Protección fisica & Acondicionamiento interior & Organización & Precisión funcional \\
\hline Protección perceptiva & Confort & Accesibilidad & Intermediación \\
\hline
\end{tabular}

Fuente: Elaboración propia.

ACE, 16 (4.6) CC BY-ND 3.0 ES | UPC Barcelona, España | Los centros de acogida para víctimas de violencia de género 


\subsection{Seguridad}

La seguridad referida a la capacidad de proteger y acoger que proporciona el espacio se liga a la casa, entendida como una segunda piel (Senosiain, 1998). Un alojamiento temporal, sin embargo, no es una piel, sino una cobertura bien tramada, especialmente importante en el caso de los CAVGe. En ellos, las mujeres no solo deben estar seguras, sino que deben sentirse a salvo de sus agresores, física y mentalmente. Una certidumbre que se puede rastrear en la protección, sea física o perceptiva.

La protección física se vincula a la presencia de personal especializado. En ningún momento debería de descartarse o reemplazarse por otro tipo de medidas puesto que, en los casos graves, podría ser la única respuesta rápida.

La protección perceptiva se revela como la 'sensación de constante seguridad'. Una cualidad fundamentalmente visual, aportada por el contexto arquitectónico y urbano del centro (Consejo de las Mujeres de Bilbao por la Igualdad, 2012). En ella influye el reconocimiento explícito del volumen físico y las condiciones de entorno del mismo, puesto que todo vecindario ejerce una tácita centinela, a través del uso del espacio público, y toda calle transitada actúa como un mecanismo de vigilancia informal durante las veinticuatro horas del día los 365 días del año (Ruíz Sánchez, 2011).

Esta cualidad se reconoce mediante cuatro indicadores, tres ligados a la protección física y un cuarto a la perceptiva.

1_Personal. La protección física se manifiesta en la aparición de un local destinado al personal encargado de la vigilancia y el control. Ha de situarse en el acceso, para controlar la entrada al interior del inmueble.

2_Material. La protección material se plasma mediante la envolvente del inmueble y del recinto, cuyos elementos deben transmitir seguridad. Evitarán, eso sí, sensación de reclusión y encarcelamiento, tan perjudicial como la de inseguridad. Se recomienda recurrir a acristalamientos de seguridad, a mecanismos de apertura y cierre controlados en las plantas bajas y en los espacios abiertos accesibles desde el exterior. También resulta de interés alejar la fachada del inmueble del espacio público, mediante la interposición de franjas de vegetación, de patios u otros elementos análogos, entre interior y exterior (véase 15_Filtros) para reforzar la sensación de protección.

3_Tecnológica. La protección tecnológica en circuito cerrado, y con conexión a las fuerzas de seguridad, completa la protección personal y material. Por otro lado, las cámaras de vigilancia visibles actúan como herramientas disuasorias ante los intentos de intrusismo y agresiones.

4_Orientativa. La organización interior debe transmitir seguridad, a través de una lectura clara de la organización distributiva. Los recorridos, sean verticales u horizontales, internos o externos han de disponerse con nitidez, facilitando identificar las diversas zonas: privadas, comunes, y administrativas. Así mismo, deben encontrarse adecuadamente iluminados, sin rincones oscuros ni ángulos muertos.

\subsection{Convivencia}

Se identifica con la disposición del espacio para facilitar las relaciones interpersonales, aspecto singular en los CAVGe, por las especiales circunstancias de las residentes. Pueden acudir a ellos en solitario; pero también hacerlo acompañadas de su prole, e incluso de sus ascendientes. Algunas son mujeres con buena salud física; otras, sin embargo, padecen enfermedades, o algún tipo de discapacidad. Visto así, el centro resulta un organismo conformado por seres heridos anímica e incluso físicamente, cuya burbuja protectora -como individuas o como núcleo familiar- ha de

ACE, 16 (46) CC BY-ND 3.0 ES | UPC Barcelona, España | Los centros de acogida para víctimas de violencia de género 
acomodarse a la idiosincrasia del centro. Y en ese acomodo, a menudo se generan tensiones derivadas de la convivencia, especialmente cuando han de acatarse unas normas prefijadas, y se ha de compartir techo con desconocidas (Rebollo Sánchez y Bravo Campanón, 2005).

De ahí que los recursos de acogida conformen un tipo híbrido. En él se mezclan los usos administrativos y terapéuticos, con los residenciales ${ }^{6}$ y los colectivos. Estos últimos pueden destinarse a un uso definido, sea para cocinar, comer o estar; o carecer de un destino certero, como el caso de los espacios intermedios, sean rellanos, corredores, galerías, o miradores entre otros (Carreiro y López, 2019; Smithson, 1974; Sánchez de Madariaga, 2009). En algunos de ellos, las mujeres pueden desempeñar alguna tarea personal, sea intelectual o manual, o simplemente 'estar'. En otros hablan e intercambian impresiones sobre la absoluta incapacidad que sienten de comunicarse con los demás (Ginzburg, 2016). Estos lugares propician el deseable equilibrio entre ensimismamiento y socialización. No requieren de muchas estancias, sino de espacios que, acogiendo distintos usos, simultánea o sucesivamente, ofrezcan calma. Y, por supuesto, accesibles para todas las usuarias.

Con estas premisas se identifican cuatro indicadores arquitectónicos ligados a la cualidad de 'convivencia'. Tres dependen de la organización funcional, y el cuarto de las condiciones de accesibilidad. Se enumeran siguiendo la prelación establecida al tratar la cualidad de la 'seguridad'.

5_Multifuncionalidad. Las estancias, sean individuales o colectivas, deben permitir desarrollar usos alternativos y complementarios, ordinarios y extraordinarios. Esto conlleva que las salas comunes dispongan de la superficie suficiente para cambiar el uso modificando la distribución del mobiliario; e incluso que admitan la formalización de distintas zonas de estar. De igual modo las células individuales deben diseñarse como habitaciones en las que se duerme, no como dormitorios.

6_Flexibilidad. Con ella se hace posible adaptar la organización del inmueble a unas circunstancias de uso no previstas inicialmente, sin necesidad de una reforma general. Este indicador está condicionado por la superficie de las piezas, por los materiales empleados en las particiones internas, y por la estructura arquitectónica del edificio y de las distintas áreas que lo integran. La flexibilidad adopta distintas maneras, no excluyentes entre sí. Una de ellas sería la que permite, por ejemplo, la convivencia de mujeres respetando las necesidades de aislamiento o socialización, acorde con la fase por la que transiten, sea inicio, curación y/o transición. Otra, la que introduce una posible variación de la superficie y el uso de las estancias, mediante paramentos móviles de separación. El primer ejemplo vendría dado por su disposición entre habitaciones, lo que facilitaría adecuarlas al número de personas que acompañen a la usuaria. El segundo, por su empleo para dividir las zonas comunes, para atender a las diversas necesidades que puedan surgir.

7_Diversidad estancial. Con ella se valora la presencia de la vegetación. La incorporación de la naturaleza en las estancias del centro, exteriores o interiores, cubiertas o descubiertas, ajardinadas o con plantación en macetas, introduce una diversidad ambiental que contribuye al confort psicológico. Un aspecto del que se ocupa la biofilia (Browning, Ryan y Clancy, 2014).

8_Accesibilidad universal. Este indicador recoge la capacidad del centro para facilitar que se habite un espacio. Los recursos de acogida deben permitir que cualquier persona transite y disfrute de los lugares comunes del centro, independientemente de su capacidad auditiva, motriz, o visual.

\footnotetext{
${ }^{6}$ Los usos residenciales pueden tener un carácter transeúnte, a modo de albergue, o un carácter estable-temporal, a modo de vivienda.
}

ACE, 16 (46) CC BY-ND 3.0 ES | UPC Barcelona, España | Los centros de acogida para víctimas de violencia de género 


\subsection{Intimidad}

Con esta cualidad se consigna la contribución de la arquitectura para favorecer la autonomía personal. Virginia Woolf (2004/1929) reivindicaba una habitación propia para las mujeres. Casi transcurrido un siglo continúan sin tenerla. Se asignan -y se les asignan- las estancias relacionadas con las labores del hogar y de los cuidados. Mientras que los hombres suelen disponer de un lugar propio en la casa, aunque sea un simple sillón.

Pocas mujeres de las que residen en los centros han tenido esa habitación propia (Carreiro et al., 2019). Ni otra que no sea la cocina, el dormitorio, o la sala común. De hecho, las mujeres no reclaman su espacio propio en los programas de vivienda. ¿Son el tendedero y una cocina bien amueblada el culmen de sus deseos? No piensan que puedan reclamarlo. Tampoco quienes legislan han imaginado tal cosa. Aunque negar a las mujeres ese espacio propio tiene consecuencias inmediatas. Afecta a la organización de la jornada diaria, en la que la serie descanso-trabajo-ocio se convierte en descansotrabajo (Cañada Vicinay, 2007). Consolida además el rol dependiente y proveedor de afectos de las mujeres, perpetuando el "dar prioridad al espacio como elemento de ordenación" (Falcó Martí, 2003: pág. 205).

El espacio propio no equivale necesariamente a un cuarto cerrado, sino a la adecuación de lugares para las actividades personales, sean manuales o intelectuales, entre las que se halla el simplemente 'no hacer nada'. Unos lugares cuya intimidad proviene de la protección acústica y visual, y del confort físico. Características ligadas a los indicadores que se definen seguidamente, continuando con la numeración proveniente de la 'seguridad' y la 'convivencia'.

9_Acondicionamiento interior. Refuerza las condiciones formales y espaciales del inmueble, asegurando tanto la protección como el confort acústico y visual. En su valoración se ha de contemplar el aislamiento acústico entre habitaciones, y entre estas y las zonas comunes. También el tamiz en la relación visual exterior-interior, logrado mediante los elementos de la fachada -vidrios translúcidos, paneles deslizantes, celosías-, complementos textiles -cortinas, estores-, o las pantallas vegetales -árboles, arbustos, enredaderas.

10_Distribución estructurada. Una apropiada organización funcional evita las interferencias entre los usos administrativos, los comunes y los privados. Con este fin, las superficies asignadas a cada uno de estos usos, y su proporción con respecto al conjunto, serán acordes con el programa de necesidades.

11_Acabados sostenibles. Se debe entender la sostenibilidad tanto en el sentido medioambiental como en el de fácil mantenimiento. Se emplearán preferentemente materiales naturales, o aquellos cuya textura y color induzca al sosiego, considerando las aportaciones de la biofilia (Browning, Ryan y Clancy, 2014).

12_Ajuar versátil. El término ajuar incluye mobiliario, menaje, y equipamiento textil. En su conjunto ha de cubrir las necesidades del habitar: alimentación, descanso, higiene, ocio y trabajo. Las condiciones más adecuadas semejan ser las de polifuncionalidad y ligereza, así como un diseño desnudo, sin adornos, con predominio de los colores claros.

\subsection{Interacción ambiental}

Una cualidad que se vincula al 'valerse por sí misma', entendida como la capacidad de leer el entorno construido y moverse en él con confianza. Exige pues que el proyectista modifique sus habituales roles de observador y director de escena para convertirse en espectador e intérprete. De esta manera, dejará de considerar la arquitectura como el escenario en el que transcurre la vida diaria (Rasmussen,

ACE, 16 (46) CC BY-ND 3.0 ES | UPC Barcelona, España | Los centros de acogida para víctimas de violencia de género 
1974/1965; Seguí, 2006), para desvelar la relación simbiótica en la que "el entorno no es meramente el escenario donde se inscribe la interacción social [...] sino que es considerado como un elemento más de la interacción" (Valera, 1999: pág. 22).

En el caso de los CAVGe, la interacción ambiental entre las mujeres y el entorno construido busca "no solamente el agrado visual y físico, sino también la utilidad de las cosas y de las habitaciones" (Simancas Yovane, 2003, pág. 69). Una circunstancia determinada por la precisión funcional, lograda a través del equilibrio entre las áreas para usos específicos e indeterminados. Y por la intermediación espacial, que relaciona el espacio exterior con el interior. Estas características se plasman a través de cuatro indicadores, enumerados según el orden establecido con anterioridad.

13_Utilidad. Refleja la adecuación entre las estancias del centro y el programa de necesidades. Ha de atender a los requerimientos físicos y psicológicos, tanto de las usuarias como del personal administrativo, terapéutico y de mantenimiento del centro.

14_In-utilidad. Complementariamente, se plantea la necesidad de generar áreas in-útiles, tanto en los ámbitos comunes como en los privados. Carentes de una función reglada, su incorporación a la vida en el centro requiere que dispongan de una buena iluminación natural y de una relación visual o física directa con el exterior. Su fin es inducir a las usuarias a apropiarse del espacio, personalizarlo y hacerlo suyo.

15_Filtros. La palabra recoge los espacios, abiertos o cerrados, construidos o naturales, dispuestos entre el acceso y las fachadas del inmueble, y el espacio exterior público. Los filtros se identifican con los espacios intermedios, sean portales, porches, terrazas, cortavientos (Carreiro y López, 2019), pero también con el vacío establecido entre la fachada y la acera. Unos lugares que es posible formalizar mediante bandas tratadas con vegetación, agua, grava u otros elementos análogos. Los filtros alejan la calle, refuerzan la seguridad perceptiva, aportan al límite que bordea el centro un espesor metafórico, a manera de foso.

16_Contexto urbanizado. La protección que, de manera informal, la ciudadanía procura a sus miembros más débiles se relaciona con los entornos urbanizados y consolidados. Por ello, el emplazamiento de un CAVGe debe situarse en un ámbito que contemple la cercanía a otras infraestructuras para la vida cotidiana, que favorezca que las mujeres se desenvuelvan por sí mismas en el devenir diario.

\section{Tres casos de estudio: Casa de Acogida de Ferrol, Centro de Emergencia de Vigo y Casa Malva de Gijón}

Antes de abordar los casos de estudio, conviene recordar el contexto en el que han surgido los CAVGe, y su fundamento ideológico, formal y organizativo. Siguen, en su mayoría, la fórmula establecida por Erin Patria Margaret Pizzey en Londres en los años 70, adoptada -y adaptada- por numerosos países del entorno occidental. Conceptualmente responden a dos enfoques, el social, y el jurídicoasistencial, independientemente de la gestión, pública o privada; del soporte organizativo, integrado en una red o autónomo; o de la condición arquitectónica del inmueble ocupado, sea reutilizado o proyectado para tal fin.

El enfoque social, aunque busca un cierto encubrimiento, encara el problema exponiendo los centros a la mirada pública, e implica tácitamente a la ciudadanía. Desde la perspectiva urbanística, este modelo se encuadra dentro de las 'infraestructuras para la vida cotidiana' (Horelli y Vepsa, 1994; Gilroy y Booth, 1999), un concepto que llega al contexto español de la mano de Sánchez de Madariaga

ACE, 16 (46) CC BY-ND 3.0 ES | UPC Barcelona, España | Los centros de acogida para víctimas de violencia de género en Galicia y Asturias, ¿modelos arquitectónicos de hogar? DOI: http://dx.doi.org/10.5821/ace.16.46.9703 
(2004). Desde el punto de vista de diseño y organización del centro, se requiere contar con seguridad personal, o al menos tecnológica.

El enfoque jurídico-asistencial prioriza los aspectos policiales y de orden público, argumento empleado para esconder la ubicación de los CAVGe. Se oculta a las mujeres en ellos para preservar su integridad física. Pero los agresores acaban encontrándolo, en cuyo caso, la única solución posible resulta ser el traslado de la mujer a una localización geográfica alejada. La seguridad en estos centros se confía a su enmascaramiento en el tejido urbano, en la red de alojamientos asistenciales. Al tratarse de algo 'oculto', en la normativa urbanística se quedan fuera del planeamiento, sin incluirse en las dotaciones urbanísticas.

Particularmente, en España la asistencia a las víctimas de violencia de género es competencia de la administración autonómica y de la local. Sus prestaciones vienen condicionadas por la tradicional equiparación entre protección a la mujer y salvaguarda de la moral, vigente hasta los años 80 del s. XX. En esa década, las reformas legislativas desarrolladas propiciaron la creación de centros públicos, casas de acogida fundamentalmente, a semejanza del modelo de Pizzey: viviendas económicas, ubicadas en barrios periféricos, reacondicionadas con una inversión mínima (Carreiro et al. 2019; Moriana Mateo, 2016). Aun a día de hoy, los centros proyectados ex novo, constituyen una excepción.

Desde el punto de vista tipológico, los CAVGe se acomodan a dos tipos residenciales: a la vivienda estándar, sea unifamiliar, o forme parte de un edificio plurifamiliar; y al inmueble especializado. Mientras que su organización funcional responde a tres modalidades: la vivienda compartida, el centro residencia, y el centro integral (Figura 3), independientemente del nombre asignado por la administración responsable.

Figura 3. Programa de los centros y participación de las mujeres en las tareas domésticas

\begin{tabular}{|c|c|c|c|c|c|c|}
\hline \multirow[b]{2}{*}{ MODALIDAD } & \multirow{2}{*}{\multicolumn{2}{|c|}{ PIEZAS }} & \multirow[b]{2}{*}{ USO } & \multicolumn{3}{|c|}{ Responsables de Limpiar } \\
\hline & & & & usuarias & técnico & profesional \\
\hline \multirow{8}{*}{$\begin{array}{l}\text {-vivienda unifamiliar } \\
\text {-vivienda en bloque }\end{array}$} & \multicolumn{2}{|c|}{ Dormitorios $1,2,0$ más camas } & privado & $\sqrt{ }$ & & \\
\hline & \multicolumn{2}{|l|}{ Aseos } & \multirow{6}{*}{ compartido } & $\sqrt{1}$ & & \\
\hline & \multicolumn{2}{|l|}{ Cocina } & & $\sqrt{ }$ & & \\
\hline & \multicolumn{2}{|l|}{ Comedor } & & $\sqrt{ }$ & & \\
\hline & \multicolumn{2}{|l|}{ Estancias } & & $\sqrt{ }$ & & \\
\hline & \multirow{2}{*}{ Otros } & juegos infantles & & $\sqrt{ }$ & & \\
\hline & & biblioteca, internet & & $\sqrt{ }$ & & \\
\hline & \multicolumn{2}{|c|}{ Área gestión (despacho, ámbito) } & privado & & $\sqrt{ }$ & \\
\hline \multirow{10}{*}{$\begin{array}{l}\text { CENTRO RESIDENCIA } \\
\text { - vivienda unifamiliar } \\
\text {-inmueble especializado }\end{array}$} & \multicolumn{2}{|c|}{ Dormitorios $1,2,0$ más camas } & privado & $\sqrt{ }$ & & \\
\hline & \multicolumn{2}{|l|}{ Aseos } & privado /compartido & $\sqrt{ }$ & & \\
\hline & \multicolumn{2}{|l|}{ Cocina } & \multirow{5}{*}{ compatido } & $\sqrt{ }$ & & \\
\hline & \multicolumn{2}{|l|}{ Comedor } & & $\sqrt{1}$ & & \\
\hline & \multicolumn{2}{|l|}{ Estancias } & & & & $\sqrt{ }$ \\
\hline & Otros & juegos infantiles & & & & $\sqrt{ }$ \\
\hline & & biblioteca, internet & & & & $\mathrm{v}$ \\
\hline & \multicolumn{2}{|c|}{ Área gestión administrativa } & \multirow{3}{*}{ colectivo } & & & $\sqrt{ }$ \\
\hline & \multirow{2}{*}{\multicolumn{2}{|c|}{$\begin{array}{l}\text { Área terapéutica } \\
\text { Atención a menores }\end{array}$}} & & & & $\sqrt{2}$ \\
\hline & & & & & & $\mathrm{v}$ \\
\hline \multirow{6}{*}{ CENTRO INTEGRAL } & \multicolumn{6}{|l|}{ opción A } \\
\hline & \multicolumn{2}{|c|}{ Unidad residencial completa } & privado & $\sqrt{ }$ & & \\
\hline & \multirow{3}{*}{$\begin{array}{l}\text { Piezas } \\
\text { comunes } \\
\text { alternativas }\end{array}$} & cocina & \multirow{3}{*}{ compartido } & $\sqrt{6}$ & & \\
\hline & & comedor & & $\sqrt{ }$ & & \\
\hline & & Sala de estar/espera & & & & $\sqrt{ }$ \\
\hline & opción B & & & & & \\
\hline -inmueble especializado & Dormitorio - & & privado & $\sqrt{ }$ & & \\
\hline & Cocina & & & $\sqrt{ }$ & & \\
\hline & Comedor & & & $\sqrt{ }$ & & \\
\hline & Estancias & & & & & $\sqrt{ }$ \\
\hline & Otros & juegos infantiles & compartido & & & $\sqrt{ }$ \\
\hline & & biblioteca, internet & & & & $\sqrt{ }$ \\
\hline & & estancias comunes & & & & $\sqrt{1}$ \\
\hline & Área gestión a & inistrativa & & & & $\sqrt{ }$ \\
\hline & Área terapéutic & & colectivo & & & $\sqrt{1}$ \\
\hline & Atención a me & & & & & $\sqrt{ }$ \\
\hline
\end{tabular}

Fuente: Elaboración propia.

ACE, 16 (46) CC BY-ND 3.0 ES | UPC Barcelona, España | Los centros de acogida para víctimas de violencia de género 
Figura 4. Plantas de los casos de estudio
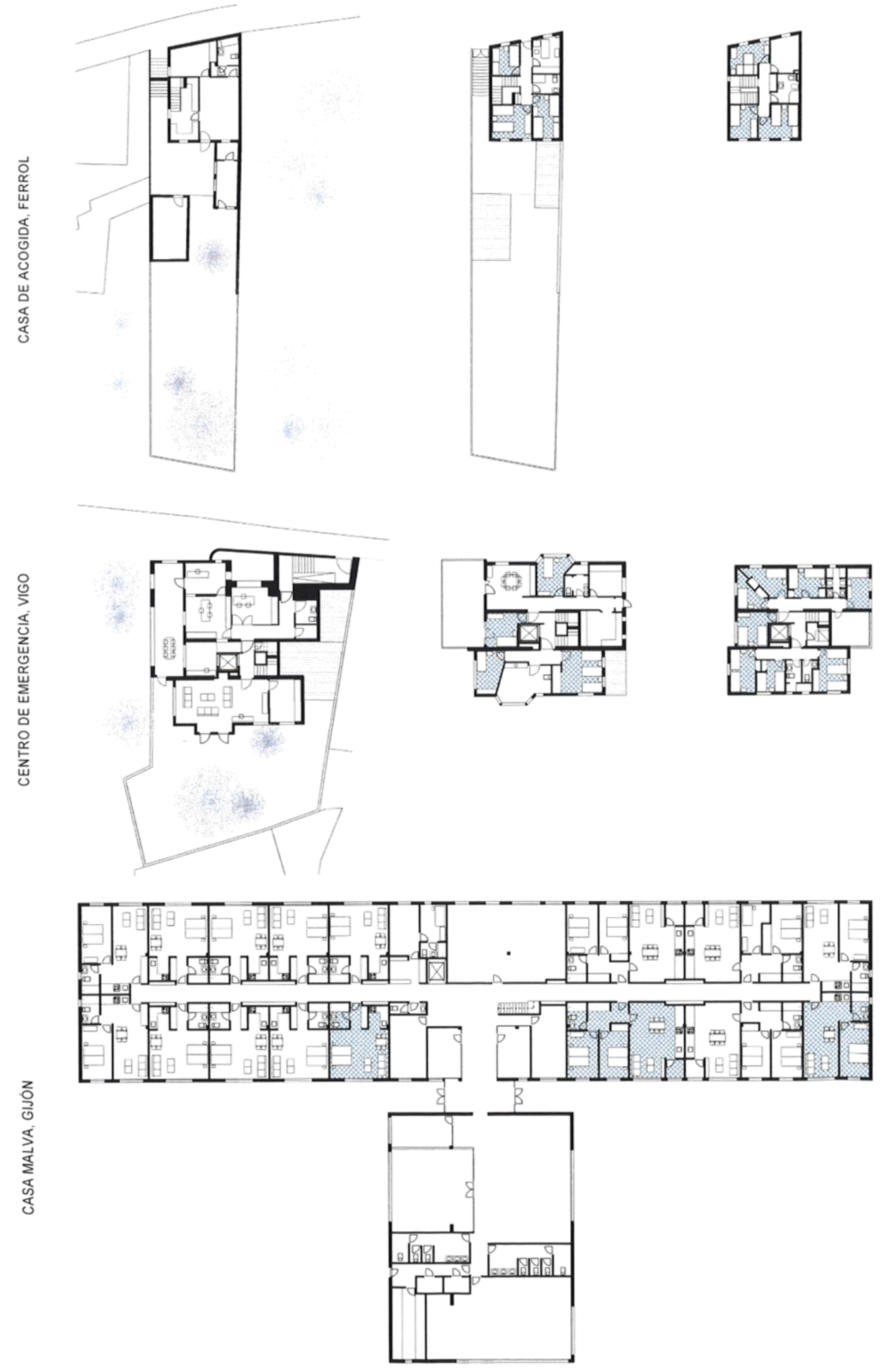

Fuente: Elaboración propia.

ACE, 16 (46) CC BY-ND 3.0 ES | UPC Barcelona, España | Los centros de acogida para víctimas de violencia de género 
Otro aspecto de la política de acogida reside en el enfoque conceptual que, salvo excepciones, se corresponde con el jurídico-asistencial y la ocultación de los centros (Carreiro et al., 2019). El resultado es evidente: no existen recursos habitacionales conocidos ni reconocidos por la ciudadanía. Ni tampoco para otros ámbitos, como la arquitectura o el urbanismo. En consecuencia, mientras el nivel de riesgo no sea elevado, cada afectada deberá resolver de manera individual el problema.

Por otra parte, es preciso calibrar la capacidad de ocupación de los centros y la forma en que esta se mide. La información pública ofrece el número de plazas de alojamiento, equivalentes al número de puestos de dormir, entendiendo por tales camas y cunas. Estas se distribuyen en habitaciones sencillas, dobles o triples, ocupadas por las residentes y si es el caso, por sus familiares. Dichos datos, siendo ciertos, distorsionan la capacidad de acogida real, que se reduce, al menos, a la mitad de lo señalado. Este sistema dificulta la comparación entre centros, por lo que al tratar los casos de estudio se considerará el número de piezas de acogimiento, y no el de puestos de dormir.

Los tres casos seleccionados (Figura 4) reflejan diferentes circunstancias. Emplazados en tres tejidos diferentes, responden a las dos tipologías residenciales enunciadas, a las tres modalidades de organización y a los dos enfoques conceptuales. Dos se integran en la Rede galega de Acollemento Red gallega de Acogida- de la Comunidad Autónoma de Galicia, y el tercero en la Red de Casas de Acogida del Principado de Asturias.

\section{- Rede de galega de Acollemento}

La política de ayuda a las víctimas de violencia de género en la Comunidad Autónoma de Galicia está sujeta al criterio de ocultación. Un enfoque muy interiorizado por gran parte de las responsables, tanto técnicas como políticas. Se coordina a través de la llamada Rede de acollemento de Galicia, integrada, en el año 2019 por siete refugios (Carreiro et al., 2019,): uno de gestión autonómica; cuatro, municipal; y dos, concertada. De los siete, se han seleccionado para este trabajo la Casa de Acollida de Ferrol, y el Centro de Emerxencia de Vigo (Peña Cristiá, 2004; Carreiro et al., 2019).

\section{- $\quad$ Red regional de casas de acogida del Principado de Asturias}

Al igual que en Galicia, el gobierno autonómico del Principado de Asturias ha establecido una Red de Casas de Acogida, formada por "un conjunto de viviendas y pisos tutelados" según informa la página web del Instituto Asturiano de la Mujer (2020). A esta Red pertenece el Centro de Atención Integral a Mujeres Víctimas de la Violencia de Género, conocido como la Casa Malva, en referencia al color de algunos de los paneles de la fachada de este edificio. Inaugurado en 2007, bajo el impulso del Gobierno del Principado, se ha planificado como un proyecto de intervención integral.

\section{- Escala de valoración}

Con el fin de valorar cada uno de estos recursos de acuerdo con los dieciséis indicadores definidos, se establece una escala graduada en cinco niveles, identificados respectivamente por un color y una puntuación numérica (Figura. 5).

Figura 5. Escala de valoración de los indicadores

\begin{tabular}{|c|c|c|}
\hline NIVEL & COLOR & PUNTUACIÓN NUMÉRICA \\
\hline Elevado & Verde obscuro & 5 \\
\hline Alto & Verde claro & 4 \\
\hline Medio & Amarillo & 3 \\
\hline Bajo & Naranja & 2 \\
\hline İnfimo & Rojo & 1 \\
\hline
\end{tabular}

Fuente: Elaboración propia.

ACE, 16 (46) CC BY-ND 3.0 ES | UPC Barcelona, España | Los centros de acogida para víctimas de violencia de género 
La puntuación global de cada centro oscila entre los extremos del entorno [16, 80] con un valor medio de 48 puntos. Al aplicarla se determina el grado de hogaridad de cada recurso, pero también se cotejan entre sí, sea a nivel general, o particularizando en los indicadores, las características y las cualidades de cada uno.

\subsection{Casa de Acogida de Ferrol, CAF}

La Casa de Acogida de Ferrol (Figura 6), el primer centro abierto en Galicia, data de 1986. De titularidad y gestión municipal, ocupa un inmueble donado por una mujer a la administración local, con la condición de convertirlo en refugio para mujeres. La vivienda unifamiliar se sitúa en una parcela estrecha y larga, con la fachada de acceso integrada en la alineación urbana, y con un jardín posterior. Ubicado en la periferia urbana (Cerasoli, 2010), la zona combina la edificación residencial de vivienda unifamiliar y plurifamiliar, con los usos comerciales. El recorrido peatonal entre la Casa y el centro urbano transcurre por un viario delimitado por largos cierres opacos.

Figura 6. Casa de Acogida de Ferrol: grados de los indicadores arquitectónicos

\begin{tabular}{|c|c|c|c|c|c|c|}
\hline \multicolumn{7}{|l|}{ Caso 1: Casa de Acogida, Ferrol } \\
\hline \multirow{2}{*}{ Indicadores arquitectónicos (16) } & \multicolumn{6}{|c|}{ Grado de optimizacion } \\
\hline & $\begin{array}{c}\text { Elevado } \\
5\end{array}$ & $\begin{array}{c}\text { Alto } \\
4\end{array}$ & $\begin{array}{c}\text { Medio } \\
3\end{array}$ & $\begin{array}{c}\text { Bajo } \\
2\end{array}$ & $\begin{array}{c}\text { Infimo } \\
1\end{array}$ & Descripción \\
\hline a1. Seguridad personal & & & & & & Ausencia de espacio propio \\
\hline a2. Seguridad material & & & & & & Elementos de protección domésticos \\
\hline a3. Seguridad tecnologica & & & & & & $\begin{array}{l}\text { Inexistencia de dispositivos } \\
\text { tecnológicos }\end{array}$ \\
\hline a4. Seguridad orientativa & & & & & & Zonificación convencional de usos \\
\hline b5, Multifuncionalidad & & & & & & $\begin{array}{l}\text { Dificultades importantes para } \\
\text { implementar usos diversos }\end{array}$ \\
\hline b6. Flexibilidad & & & & & & $\begin{array}{l}\text { Espacios fjos con nulas opciones de } \\
\text { reorganizacion }\end{array}$ \\
\hline b7. Diversidad estancial & & & & & & $\begin{array}{l}\text { Potencialidad del espacio ajardinado } \\
\text { exterior }\end{array}$ \\
\hline b8. Accesibilidad universal & & & & & & $\begin{array}{l}\text { Imposibilidad de moverse con } \\
\text { facilidad }\end{array}$ \\
\hline c9. Acondicionamiento interior & & & & & & Ineficaź protección acústica interior \\
\hline c10. Distribucion estructurada & & & & & & Minima disposición funcional \\
\hline c11. Acabados sostenibles & & & & & & $\begin{array}{l}\text { Materiales convencionales de escaso } \\
\text { confort psicologico }\end{array}$ \\
\hline c12. Ajuar versatil & & & & & & $\begin{array}{l}\text { De heterogénea procedencia, posee } \\
\text { una nula versatilidad }\end{array}$ \\
\hline d13. Utilidad & & & & & & $\begin{array}{l}\text { Programa estánđar básico e } \\
\text { incompleto }\end{array}$ \\
\hline d14. In-utilidad & & & & & & $\begin{array}{l}\text { Carenciáa de espacios para la } \\
\text { 'apropiación personal' }\end{array}$ \\
\hline d15. Filtros & & & & & & $\begin{array}{l}\text { Falta de espacios intermedios } \\
\text { internos y externos }\end{array}$ \\
\hline d16. Contexto urbanizado & & & & & & $\begin{array}{l}\text { En un área consolidada sin servicios } \\
\text { urbanos en su proximidad }\end{array}$ \\
\hline
\end{tabular}

Fuente: Elaboración propia.

Se organiza según el modelo de vivienda compartida. Las residentes se encargan, por turnos, de la totalidad de las tareas domésticas, incluida la preparación de la comida. Con una capacidad de ocupación de quince personas -trece adultos y dos bebés- dispone de seis dormitorios, tres baños, un despacho, una biblioteca, una zona de juego infantil, cocina, comedor-estancia, lavandería, almacén, y jardín posterior (Figura 4). La iluminación natural de la sala de estar y la cocina es adecuada, parca en los dormitorios, y muy débil en la sala de juego infantil. El amueblamiento de las zonas comunes es acorde a los usos: cocinar, comer y estar; el de los dormitorios está constituido

ACE, 16 (46) CC BY-ND 3.0 ES | UPC Barcelona, España | Los centros de acogida para víctimas de violencia de género 13 en Galicia y Asturias, ¿modelos arquitectónicos de hogar? DOI: http://dx.doi.org/10.5821/ace.16.46.9703 
por camas y/o literas según su capacidad, armario y en ocasiones, un escritorio. El centro no está adaptado a usuarias con discapacidad física motora: no dispone de ascensor, y los corredores son estrechos. Por su parte, los vecinos conocen el uso al que se destina el centro, e incluso llegan a interactuar con las mujeres, aunque, conforme a la política oficial de ocultamiento, se manifiestan indiferentes a su presencia. Carece de personal de vigilancia, confiando la protección al video portero, a la mirilla de la puerta, y a las rejas en todas las ventanas de la planta de acceso, y del semisótano.

\subsection{Centro de Emergencia de Vigo, CEMVI}

El Centro de Emergencia de Vigo (Figura 7), de gestión autonómica, se inauguró en 1991. Ocupa un inmueble de titularidad municipal que, al igual que en Ferrol, procede de una donación particular. La residencia unifamiliar exenta con jardín ocupa una esquina de una manzana céntrica, lo que le confiere una considerable amplitud visual. Emplazada dentro de la trama urbana consolidada, se ubica en las proximidades de una comisaría de la Policía Nacional.

Figura 7. Centro de Emergencia de Vigo: grados de los indicadores arquitectónicos

\begin{tabular}{|c|c|c|c|c|c|c|}
\hline \multicolumn{7}{|c|}{ Caso 2: Centro de Emergencia, Vigo } \\
\hline \multirow{2}{*}{ Indicadores arquitectonicos (16) } & \multicolumn{6}{|c|}{ Grado de optimización } \\
\hline & $\begin{array}{c}\text { Elevado } \\
5\end{array}$ & $\begin{array}{c}\text { Alto } \\
4\end{array}$ & $\begin{array}{c}\text { Medio } \\
3\end{array}$ & $\begin{array}{c}\text { Bajo } \\
2\end{array}$ & $\begin{array}{c}\text { Infimo } \\
1\end{array}$ & Descripciôn \\
\hline a1. Seguridad personal & & & & & & Ausencia de espacio propio \\
\hline a2. Seguridad material & & & & & & $\begin{array}{l}\text { Dispone de elementos } \\
\text { arquitectónicos adecuados }\end{array}$ \\
\hline a3. Seguridad tecnologica & & & & & & $\begin{array}{l}\text { Presencia de dispositivos } \\
\text { tecnologicos apropiados }\end{array}$ \\
\hline a4. Seguridad orientativa & & & & & & $\begin{array}{l}\text { Compartimentación excesiva que } \\
\text { dificulta la orientación }\end{array}$ \\
\hline b5. Muliffuncionalidad & & & & & & $\begin{array}{l}\text { Una limitada superficie implica la } \\
\text { excesiva especializacion de usos }\end{array}$ \\
\hline b6. Flexibilidad & & & & & & Espacios fijos de superficie minima \\
\hline b7. Diversidad estancial & & & & & & $\begin{array}{l}\text { Potencialidad del espacio ajardinado } \\
\text { exterior }\end{array}$ \\
\hline b8. Accesibilidad universal & & & & & & Acondicionamiento mínimo \\
\hline c9. Acondicionamiento interior & & & & & & $\begin{array}{l}\text { Insuficiente protección ácústica } \\
\text { interior }\end{array}$ \\
\hline c10. Distribucion estructurada & & & & & & $\begin{array}{l}\text { Condicionada por los muros de carga } \\
\text { estructurales }\end{array}$ \\
\hline c11. Acabados sostenibles & & & & & & $\begin{array}{l}\text { Materiales convencionales de escaso } \\
\text { confort psicologico }\end{array}$ \\
\hline c12. Ajuar versatil & & & & & & $\begin{array}{l}\text { Heterogéneo y común, con escasa } \\
\text { versatilidad }\end{array}$ \\
\hline d13. Utilidad & & & & & & $\begin{array}{l}\text { Programa estándar básico e } \\
\text { incompleto }\end{array}$ \\
\hline d14. In-utilidad & & & & & & $\begin{array}{l}\text { Carencia de espacios para la } \\
\text { "apropiación personal" }\end{array}$ \\
\hline d15. Filtros & & & & & & $\begin{array}{l}\text { Existencia parcial de espacios } \\
\text { intermedios }\end{array}$ \\
\hline d16. Contexto urbanizado & & & & & & $\begin{array}{l}\text { En el centro urbano, con múliples } \\
\text { equipamientos próximos }\end{array}$ \\
\hline
\end{tabular}

Fuente: Elaboración propia.

Organizativamente se clasifica como centro residencia, con una zona administrativa, una terapéuticoeducacional, y una residencial (Figura 4). La limpieza de la zona residencial es responsabilidad de las usuarias, y la de las zonas no residenciales, de personal especializado. Las comidas principales las sirve una empresa de restauración, destinándose la cocina para preparar desayunos y meriendas, o realizar alguna actividad programada. Cuenta con once dormitorios -uno reservado para las trabajadoras- que ofrecen cama a veinte personas. Dispone de una sala común, comedor, cuatro

ACE, 16 (46) CC BY-ND 3.0 ES | UPC Barcelona, España | Los centros de acogida para víctimas de violencia de género 
baños completos - uno de ellos accesible- y dos aseos; lavandería, y varios locales de almacenaje. La accesibilidad se ha resuelto bajo un criterio de mínimos: una plataforma en el acceso, y un ascensor interno. Las estrechas dimensiones de los pasillos, y los escalones interpuestos entre las estancias y el jardín le impiden disfrutar de una accesibilidad universal.

El centro se enmarca en la política común de la red gallega, basada en la ocultación, pese a lo que el centro se identifica como Casa de la Mujer, sin que ello suponga un desvelamiento directo de su función de refugio. El vecindario en palabras de las responsables se mantiene 'neutro', sin muestras de curiosidad ni de interrelación con las mujeres. Aunque carece de personal de vigilancia, está dotado de videocámaras, tanto en los accesos exteriores, como en el patio-jardín. En este sentido, la presencia de la policía genera confianza en las usuarias, en palabras de la directora del centro.

\subsection{La Casa Malva de Gijón, centro de atención integral a mujeres víctimas de la violencia de género}

Se ubica este centro (Figura 8) en un polígono residencial, en un barrio en expansión dotado con equipamientos y zonas verdes, y espacios para el comercio y el ocio (Merelas, 2017; Carreiro et al., 2019). Ocupa la esquina de una parcela destinada principalmente a 'infraestructuras para la vida cotidiana'. Incluye en su programa alojamiento, actividades terapéuticas y asesoramiento, tanto para las mujeres como para su prole. Representa uno de los escasos modelos españoles de enfoque social, claramente reconocible por la ciudadanía.

Figura 8. Casa Malva de Gijón: grados de los indicadores arquitectónicos

\begin{tabular}{|c|c|c|c|c|c|c|}
\hline \multicolumn{7}{|l|}{ Caso 3: Casa Malva, Gijón } \\
\hline \multirow{2}{*}{ Indicadores arquitectónicos (16) } & \multicolumn{6}{|c|}{ Grado de optimización } \\
\hline & $\begin{array}{c}\text { Elevado } \\
5\end{array}$ & $\begin{array}{c}\text { Alto } \\
4\end{array}$ & $\begin{array}{c}\text { Medio } \\
3\end{array}$ & $\begin{array}{c}\text { Bajo } \\
2\end{array}$ & $\begin{array}{c}\text { Infimo } \\
1\end{array}$ & Descripción \\
\hline a1. Seguridad personal & & & & & & Existencia de espacio especificos \\
\hline a2. Seguridad material & & & & & & $\begin{array}{l}\text { Dispone de elementos } \\
\text { arquitectónicos adecuados }\end{array}$ \\
\hline a3. Seguridad tecnologica & & & & & & $\begin{array}{l}\text { Presencia de dispositivos } \\
\text { tecnologicos apropiados }\end{array}$ \\
\hline a4. Seguridad orientativa & & & & & & $\begin{array}{l}\text { Lectura clara y sencilla de la } \\
\text { organización espacial }\end{array}$ \\
\hline b5. Multifuncionalidad & & & & & & $\begin{array}{l}\text { Estancias susceptibles de albergar } \\
\text { usos diversos }\end{array}$ \\
\hline b6. Flexibilidad & & & & & & $\begin{array}{l}\text { Capacidad de variar la estructura } \\
\text { organizativa }\end{array}$ \\
\hline b7. Diversidad estancial & & & & & & Potencialidad del espacio exterior \\
\hline b8. Accesibilidad universal & & & & & & $\begin{array}{l}\text { Adecuada accesibilidad motriz y } \\
\text { adaptable visual y acústicamente }\end{array}$ \\
\hline c9. Acondicionamiento interior & & & & & & $\begin{array}{l}\text { Notable, salvo por la falta de luz } \\
\text { natural en corredores }\end{array}$ \\
\hline c10. Distribución estructurada & & & & & & $\begin{array}{l}\text { Buena organización clara y bien } \\
\text { dimensionada }\end{array}$ \\
\hline c11. Acabados sostenibles & & & & & & $\begin{array}{l}\text { Refuerzo apropiado de la calidad } \\
\text { del espacio }\end{array}$ \\
\hline c12. Ajuar versátil & & & & & & $\begin{array}{l}\text { Mobiliario acorde con la flexibilidad } \\
\text { y multifuncionalidad }\end{array}$ \\
\hline d13. Utilidad & & & & & & $\begin{array}{l}\text { Incorporación de espacio propio al } \\
\text { programa de necesidades }\end{array}$ \\
\hline d14. In-utilidad & & & & & & $\begin{array}{l}\text { Existencia de espacios para la } \\
\text { 'apropiación personal' }\end{array}$ \\
\hline d15. Filtros & & & & & & $\begin{array}{l}\text { Espacios intermedios que cumplen } \\
\text { esta función }\end{array}$ \\
\hline d16. Contexto urbanizado & & & & & & $\begin{array}{l}\text { En un área consolidada, con } \\
\text { mültiples equipamientos }\end{array}$ \\
\hline
\end{tabular}

Fuente: Elaboración propia.

ACE, 16 (46) CC BY-ND 3.0 ES | UPC Barcelona, España | Los centros de acogida para víctimas de violencia de género 
El recurso se conforma como un recinto delimitado, que incluye los edificios de alojamiento y servicios, un aparcamiento propio en superficie, y un patio pavimentado con un área de juego infantil. Se organiza en dos edificios. El de menor extensión corresponde a un bloque plurifamiliar autónomo, con doce viviendas para usuarias en fase de transición a la vida ordinaria. Mientras, el de mayor superficie formaliza el centro propiamente dicho, organizado en un área colectiva -servicios administrativos, terapia, asesoría, y estancias comunes-, y dos áreas residenciales (Figura 4). Una, con diez unidades de acogida; y otra, con veinte de larga estancia.

Cada usuaria se aloja junto con sus familiares en una unidad residencial: 'su' casa. Mientras permanezca en el centro ha de responsabilizarse de ella. Las zonas comunes incluyen una cocina y un comedor colectivo, de libre disposición, cuya limpieza corresponde a quienes las usen. La compra de productos de alimentación e higiene recae en la gobernanta.7

Las unidades residenciales, tanto de acogida como de larga estancia, responden al programa de necesidades de una vivienda estándar: recibidor, pasillo, cocina, salón-comedor, baño, y lavaderotendedero, con una, dos o tres habitaciones, amuebladas adecuadamente.

\section{Discusión}

Descrito y analizado cada centro por separado, es de interés ponerlos en relación, cotejando los datos generales y el grado de cumplimiento de los diversos indicadores.

\subsection{Datos generales}

Gestión. El centro de Ferrol es responsabilidad municipal, mientras los de Vigo y Gijón dependen de las respectivas autoridades autonómicas. La limitada capacidad inversora municipal explica, en parte, las diferencias observadas en el mantenimiento y cuidado del primero, con respecto a los otros dos.

Tipología edificatoria. Frente a los centros de la red gallega, ubicados en inmuebles residenciales que ya existían, el edificio que aloja el centro asturiano se encuadra en un tipo específico nuevo, centro de acogida para víctimas de violencia de género.

Tipo de recurso. La Casa de Ferrol se asimila a una vivienda compartida, con las usuarias encargadas del mantenimiento diario. El Centro de Vigo a un centro residencia, y la Casa Malva, a un centro integral, ambos con un mantenimiento mixto usuarias-personal externo.

\subsection{Cualidades}

- $\quad$ Seguridad

1_Personal. La Casa de Ferrol carece de un espacio específico para el personal de seguridad, o la capacidad de disponer de él. Lo mismo sucede en el Centro de Vigo, aunque en este podría

\footnotetext{
${ }^{7}$ La gestión de los centros de acogida se estructura en torno a la directora del centro, la gobernanta, la educadora social, y otro personal como psicóloga, nutricionista, enfermera, terapeuta, etc. según el programa que el centro desarrolle. La gobernanta se encarga de la compra de víveres y productos del hogar, y su reparto, en función de lo solicitado por cada usuaria para una semana. En la Casa Malva trabajan, aproximadamente, 18 funcionarias: 5 de la Red, y 13 auxiliares. A mayores, se les suma el personal externo, para la seguridad o la limpieza de las zonas comunes.
}

ACE, 16 (46) CC BY-ND 3.0 ES | UPC Barcelona, España | Los centros de acogida para víctimas de violencia de género en Galicia y Asturias, ¿modelos arquitectónicos de hogar? DOI: http://dx.doi.org/10.5821/ace.16.46.9703 
incorporarse con una intervención mínima. Por su parte, la Casa Malva cuenta con un local destinado a tal fin, ubicado en el acceso al centro.

2_Material. En la Casa de Ferrol la seguridad material se confía a elementos empleados habitualmente en las viviendas: rejas en los huecos con frente a la calle, mirilla y videoportero. Hábilmente, se refuerza la seguridad material con la distribución de usos, de tal modo que las estancias cuyas ventanas dan a la vía pública en planta baja se destinan a despacho y a alcoba ocasional. En el Centro de Vigo, y en la Casa Malva de Gijón, la seguridad material viene dada por la posición de los respectivos inmuebles con respecto a las alineaciones viarias y a la diferencia de cota entre las calles y la planta baja. En ambos casos, las fachadas se encuentran retranqueadas, separadas de la calle, y las plantas bajas elevadas con respecto a ella.

3_Tecnológica. En Ferrol, la Casa de Acogida carece de esta instalación, que sí está presente tanto en Centro de Vigo, como en la Casa de Gijón.

4_Orientativa. La semejanza de la Casa de Ferrol con una vivienda estándar, en cuanto a superficie y distribución, garantiza la seguridad orientativa. Sin embargo, en el caso de Vigo, a pesar de ser también una vivienda unifamiliar convencional, la constreñida superficie y la compartimentada distribución dificultan el entendimiento intuitivo del centro. Por el contrario, la Casa Malva aporta la necesaria seguridad orientativa, por medio de las circulaciones bien estructuradas, y de la relación visual entre interior y exterior.

\section{- $\quad$ Convivencia}

5_Multifuncionalidad. La mínima superficie presente en los locales de la Casa de Ferrol, y del Centro de Vigo, dificultan la multifuncionalidad. En ambos, la única pieza multifuncional es la sala de estar, que se usa como lugar de reunión formal e informal, zona de juegos, improvisado comedor, o sala de televisión. El centro asturiano ofrece, por el contrario, una valoración favorable del indicador. La superficie de las zonas comunes admite usos complementarios y alternativos, tal y como sucede en el comedor, las zonas de espera, las aulas de actividades, o la ludoteca infantil.

6_Flexibilidad. Tanto en Ferrol como Vigo, la superficie y la rigidez de las particiones comprometen la flexibilidad. No hay posibilidad de introducir variaciones en la organización, ni con el mobiliario, ni tampoco de unir o separar ámbitos dentro de una misma estancia. Por el contrario, en Gijón, tanto las dependencias de la vivienda como las zonas comunes permiten variarla, sin necesidad de modificar la estructura general del centro, ni de las propias viviendas.

7_Diversidad estancial. Los tres centros disponen de un espacio exterior que, a pesar de su potencial efecto terapéutico, no forma parte de la vida diaria de los mismos. Tampoco se detecta en ellos ninguna intención biofílica, sin elementos que evoquen en su interior la naturaleza. El patio-jardínhuerto de la Casa de Ferrol apenas se aprovecha en la superficie pavimentada ligada al estar, la lavandería y una zona de almacenaje. El jardín del Centro de Vigo está tratado como una zona residual, desligado de sus estancias. Por su parte, en Gijón, la superficie exterior está prácticamente asfaltada en su totalidad, sin intención de incorporar la naturaleza al centro.

8_Accesibilidad universal. La accesibilidad debe entenderse como una limitación de la Casa de Ferrol, vetada a las mujeres con discapacidad motriz. Es una carencia difícil de resolver, aunque que no la invalida como refugio. El Centro de Vigo, por su parte, dispone de la accesibilidad mínima, lograda con una plataforma elevadora en el acceso desde la calle, el ascensor interior, y un baño adaptado. Pese a estas mejoras, la movilidad interior está muy comprometida por las dimensiones de los pasillos y las habitaciones. La Casa Malva, de construcción reciente, es plenamente accesible, incluso

ACE, 16 (46) CC BY-ND 3.0 ES | UPC Barcelona, España | Los centros de acogida para víctimas de violencia de género en Galicia y Asturias, ¿modelos arquitectónicos de hogar? DOI: http://dx.doi.org/10.5821/ace.16.46.9703 
podría alcanzar la accesibilidad universal incorporando las instalaciones necesarias para las discapacidades auditivas y visuales.

- Intimidad

9_Acondicionamiento interior. Tanto la Casa de Ferrol como el Centro de Vigo presentan unos valores similares en cuanto al acondicionamiento visual. La protección visual se garantiza por la configuración formal de los inmuebles, con ventanas convencionales y tabiques y puertas opacas en las habitaciones. La protección acústica interior es deficiente en ambos casos. Sin embargo, la protección acústica con el exterior, en el Centro de Vigo, es mejor debido a su posición con respecto al espacio público. Por su parte, la Casa Malva presenta un acondicionamiento interior adecuado, tanto visual como acústico.

10_Distribución estructurada. Una distribución de una 'vivienda' familiar no parece resolver, a día de hoy, las necesidades de habitabilidad de un CAVGe. Esta es una situación común tanto en la Casa de Ferrol como en el Centro de Vigo. Es un tema conceptual: un recurso habitacional no es una vivienda al uso, ni un hotel. Para conseguir una estructura adecuada, ambos centros requieren una reforma sustancial, o incluso una ampliación que evite la reducción de su capacidad de acogida. El contrapunto lo proporciona la Casa Malva, cuya estructura puede tomarse como referencia de partida para un proyecto arquitectónico.

11_ Acabados sostenibles. En los tres centros se han empleado materiales convencionales, de fácil mantenimiento, sin que ello implique que sean sostenibles medioambientalmente, de acuerdo con las normativas y regulaciones actuales.

12_Ajuar versátil. La Casa de Ferrol y el centro de Vigo disponen de un ajuar heterogéneo, fruto de la acumulación de donaciones junto con algunas compras. En ambos se aprovecha 'lo que se tiene', sin considerar la versatilidad como un requerimiento. La Casa Malva dispone de un ajuar y un mobiliario más funcional, acorde con las características generales del centro.

\section{- Interacción Ambiental}

13_ Utilidad. Los tres recursos están pensados desde una óptica utilitaria, que asigna a todas las estancias un uso específico. La diferencia entre Ferrol y Vigo, por un lado, y la Casa Malva, por otro, estriba en la mayor superficie por usuaria de esta última.

14_ In-utilidad. Los tres centros carecen de espacios con estas características. Si bien, las áreas comunes de la Casa Malva dedicadas a la espera y a la estancia informal podrían identificarse con estos espacios in-útiles, susceptibles de ocuparse sin una finalidad prefijada.

Los tres, sin embargo, disponen de un potencial espacio in-útil: el patio/jardín, aunque carente del mínimo tratamiento -vegetación, algún mobiliario- que dé pie a las relaciones espontáneas. Curiosamente, durante la visita a los centros de Ferrol y de Vigo, se observó que, en uno y otro, la lavandería acogía la charla informal de un reducido grupo de usuarias. Una muestra de la necesidad de los espacios in-útiles.

15_Filtros. La Casa de Ferrol carece de filtros tanto internos como externos: del interior se pasa al exterior y viceversa, sin elementos intermedios. Mientras en Vigo y en Gijón la posición de los inmuebles en la parcela define elementos intermedios, tanto en la entrada como en el resto de fachadas. Estos dos últimos centros se conectan con la vía pública a través de un zaguán, un patio o zonas ajardinadas.

ACE, 16 (46) CC BY-ND 3.0 ES | UPC Barcelona, España | Los centros de acogida para víctimas de violencia de género en Galicia y Asturias, ¿modelos arquitectónicos de hogar? DOI: http://dx.doi.org/10.5821/ace.16.46.9703 
16_Contexto urbanizado. Los tres centros se ubican en entornos urbanos con distinto grado de consolidación. En Ferrol, las dotaciones docentes, sanitarias o sociales se hallan a menos de quince minutos caminando (Carreiro et al., 2019), pero con recorridos a lo largo de calles flanqueadas por muros opacos, carentes de un ambiente urbano acogedor. Por su parte, el Centro de Vigo favorece la vida diaria, al estar circundado de calles transitadas. En el Centro de Gijón se observa una situación intermedia entre las dos anteriores. Ubicado en un polígono residencial, la cercanía a las infraestructuras urbanas facilita el día a día a las usuarias, pero dispone de menos 'vida' comercial que en el caso de Vigo

\section{- $\quad$ Síntesis}

La comparación realizada entre los centros se traslada a la Figura 9, lo que permite valorar el cumplimiento de los indicadores de una manera agregada. Considerados en su conjunto los centros no satisfacen los requerimientos de hogaridad. Esta afirmación debe ser matizada, ya que frente a las bajas valoraciones de Ferrol y Vigo, la Casa Malva ofrece una valoración notable. Su valoración coincide en un único indicador: la diversidad estancial. Con respecto a la misma, los tres muestran un claro margen de mejora.

La Casa de Ferrol arroja unos valores muy similares en las cuatro cualidades analizadas, siempre por debajo de la media. Mientras, el Centro de Vigo presenta unos valores medios en cuanto a la seguridad y la interacción ambiental, pero insuficientes en lo que respecta a convivencia e intimidad. A su vez, la Casa Malva ofrece una valoración sobresaliente en seguridad e intimidad, y notable en convivencia e interacción ambiental. Los datos incorporados en la Figura 9 ofrecen una lectura más amplia, que liga la hogaridad con otros aspectos como la fecha de creación, el enfoque conceptual, la gestión del centro y la tipología del inmueble.

Si atendemos a la fecha de creación, se observa que Ferrol, establecido en 1986 -el primer recurso de Galicia, una apuesta innovadora en su momento- apenas ha evolucionado en más de treinta años. Otro tanto sucede con el de Vigo, fundado en 1990, que no da una respuesta acorde con los requerimientos actuales, a pesar de las mejoras introducidas. La Casa Malva, inaugurada en 2007, recoge la experiencia acumulada, cambiando el enfoque. Es también el resultado de una importante inversión económica, si lo comparamos con los recursos de la red gallega. Una cuestión fundamental: sin asignaciones presupuestarias decididas, no es posible mejorar las condiciones de los centros, independientemente de cualquier otra circunstancia.

El enfoque conceptual dado a los centros repercute de manera sustancial en los aspectos económicos, y por extensión, en la gestión y la tipología de los inmuebles destinados a este fin. La ocultación, como enfoque predominante, representa una clara excusa para no invertir en los centros. Carecen de visibilidad pública, no se pueden difundir como logros, con fines electorales y, por otro lado, afectan a una pequeña parte de la ciudadanía. La situación de las usuarias de los centros es lo suficientemente lesiva, para que manifiesten malestar o desacuerdo. Como ha apuntado alguna responsable, sólo acuden a ellos quienes carecen de cualquier otro medio. Conviene apuntar que la información pública sobre los centros es mínima, y en ella no se contempla la inversión económica estimada. Sin embargo, una lectura analítica de la situación actual muestra su precariedad, y un cierto voluntarismo.

El discurso que acompaña la política de lucha contra la violencia de género ha omitido las condiciones habitables de los centros. Las recomendaciones y sugerencias no plantean su categorización como una infraestructura para la vida cotidiana dentro de las dotaciones urbanas. No se planifican y por tanto no se dotan de los imprescindibles recursos financieros. En este sentido, continúan siendo una cuestión privada, de buena voluntad, no de derechos ciudadanos.

ACE, 16 (46) CC BY-ND 3.0 ES | UPC Barcelona, España | Los centros de acogida para víctimas de violencia de género en Galicia y Asturias, cmodelos arquitectónicos de hogar? DOI: $\underline{\text { http://dx.doi.org/10.5821/ace.16.46.9703 }}$ 
Figura 9. Datos generales y los resultados comparados para los tres casos de estudio

\begin{tabular}{|c|c|c|c|c|}
\hline \multicolumn{5}{|c|}{ Centros de acogida para victimas de violencia de género. CONDICIONES para generar un 'HOGAR' } \\
\hline DATOS GENERALES & $\begin{array}{l}\text { CASO } 1 \\
\text { FERROL }\end{array}$ & $\begin{array}{l}\text { CASO } 2 \\
\text { VIGO }\end{array}$ & $\begin{array}{l}\text { CASO } 3 \\
\text { GINON }\end{array}$ & \\
\hline AÑO DE INAUGURACION OEL CENTRO & 1986 & 1991 & 2007 & \\
\hline \multirow{3}{*}{$\begin{array}{l}\text { TITULARIDAD DEL INMUEBLE } \\
\text { GESTION } \\
\text { TIPODEL INMUEBLE }\end{array}$} & Municipal & Municipal & Autonómica & \\
\hline & Municipal & Autonómica & Autonómica & \\
\hline & Vivienda & Vivienda & infraestructura & \\
\hline TIPO DEL RECURSO & $\begin{array}{l}\text { Vivienda- } \\
\text { compartida }\end{array}$ & $\begin{array}{c}\text { Centro- } \\
\text { residencia }\end{array}$ & \begin{tabular}{|l|} 
Centro- \\
integral
\end{tabular} & \\
\hline ASIGNACIÓN USO PLAN GENERAL & Asistencial & Asistencial & Asistencial & \\
\hline ÁSIGNACIÓN DE USO EN CATASTRO & Residencial & Residencial & $\begin{array}{l}\text { Benéfico- } \\
\text { Sanitaria }\end{array}$ & \\
\hline CAPACIDAD: DORMITORIOSIUNIDADES RESIDENCIALES & 6 & 11 & 30 & \\
\hline CAPACIDAD: PERSONAS & 15 & 20 & $>30$ & \\
\hline
\end{tabular}

\begin{tabular}{|c|c|c|c|c|c|c|c|}
\hline \multicolumn{8}{|c|}{ Hogar: cualidades, caracteristicas e indicadores } \\
\hline \multirow{2}{*}{ CUALIDADES } & \multirow{2}{*}{ CARACTERISTICAS } & \multicolumn{6}{|l|}{ GRADO DE CUMPLIMIENTO } \\
\hline & & $\begin{array}{l}\text { INDICADORES } \\
\text { ARQUITECTONICOS (16) }\end{array}$ & $\begin{array}{l}\text { CASO } 1 \\
\text { FERROL }\end{array}$ & $\begin{array}{l}{ }_{\mathrm{CASO}} 2 \\
\mathrm{VIGO}\end{array}$ & $\begin{array}{l}\text { CASO } 3^{\text {GINON }} \\
\text { (n) }\end{array}$ & \multicolumn{2}{|c|}{ MEDIA } \\
\hline \multirow{4}{*}{ SEGURIDAD } & \multirow{4}{*}{ PROTECCIÓN FISICA } & SEGURIDAD PERSONAL & 1 & 1 & 5 & 2,33 & \\
\hline & & SEGURIDAD MATERIAL & 2 & 4 & 5 & 3,66 & \\
\hline & & $\begin{array}{l}\text { SEGURIDAD } \\
\text { TECNOLOGICA }\end{array}$ & 1 & 4 & 5 & 3,33 & \\
\hline & & $\begin{array}{l}\text { SEGURIDAD } \\
\text { ORIENTATIVA }\end{array}$ & 3 & 3 & 4 & 3,33 & \\
\hline \multicolumn{3}{|c|}{$\begin{array}{l}\text { E Parcial } 1{ }^{2} \text { Cualidad } \\
\text { (max. 201 min. } 4 \text { / media 12) }\end{array}$} & 7 & 11 & 19 & & 12,33 \\
\hline \multirow{4}{*}{ CONVIVENCIA } & \multirow{3}{*}{ ORGANIZACIÓN } & MULTIFUNCIONALIDAD & 2 & 1 & 3 & 2,66 & \\
\hline & & FLEXIBILIDAD & 1 & 1 & 4 & 2,00 & \\
\hline & & DIVERSIDAD ESTANCIAL & 3 & 3 & 3 & 3,00 & \\
\hline & ACCESIBILIDAD & $\begin{array}{l}\text { ACCESIBILIDAD } \\
\text { UNIVERSAL. }\end{array}$ & 1 & 3 & 4 & 2,66 & \\
\hline \multicolumn{3}{|c|}{$\begin{array}{l}\text { SParcial } 2^{2} \text { cualidad } \\
\text { (máx.20/ min. 4/media 12) }\end{array}$} & 7 & 8 & 16 & & 11,33 \\
\hline \multirow{4}{*}{ INTIMIDAD } & $\begin{array}{l}\text { PROTECCION } \\
\text { ACUSTICA Y VISUAL }\end{array}$ & $\begin{array}{l}\text { ACONDICIONAMIENTO } \\
\text { INTERIOR }\end{array}$ & 2 & 3 & 4 & 2,66 & \\
\hline & \multirow{3}{*}{ CONFORT } & $\begin{array}{l}\text { DISTRIBUCION } \\
\text { ESTRUCTURADA }\end{array}$ & 2 & 2 & 4 & 2,66 & \\
\hline & & $\begin{array}{l}\text { ACABADOOS } \\
\text { SOSTENIBLES } \\
\end{array}$ & 3 & 3 & 4 & 2.66 & \\
\hline & & AJUAR VERSATIL & 1 & 2 & 4 & 2,33 & \\
\hline \multicolumn{3}{|c|}{$\begin{array}{l}\text { E Parcial } 3^{a} \text { cualidad } \\
\text { (max. 201 min. } 4 \text { /media 12) }\end{array}$} & 8 & 10 & 20 & & 10,33 \\
\hline \multirow{4}{*}{$\begin{array}{l}\text { INTERACCIÓN } \\
\text { AMBIENTAL }\end{array}$} & \multirow[t]{2}{*}{$\begin{array}{l}\text { PRECISIÓN } \\
\text { FUNCIONAL }\end{array}$} & UTILIDAD & 3 & 3 & 4 & 3,33 & \\
\hline & & IN-UTILIDAD & 1 & 1 & 4 & 2.00 & \\
\hline & \multirow[t]{2}{*}{ INTERMEDIACIOON } & FILTROS & 1 & 3 & 4 & 2.66 & \\
\hline & & CONTEXTO URBANIZADO & 3 & g & 4 & 4.00 & \\
\hline \multicolumn{3}{|c|}{$\begin{array}{l}\text { EParcial } 4^{2} \text { cualidad } \\
\text { (max.20 min. } 4 / \text { media 12) }\end{array}$} & 8 & 12 & 16 & & 12,00 \\
\hline \\
\hline \multicolumn{3}{|c|}{$\begin{array}{l}\text { E Total cualidades } \\
\text { (máx } 80 \text { imin. } 16 / \text { media } 48 \text { ) }\end{array}$} & 3c & 41 & 67 & 46.00 & \\
\hline
\end{tabular}

Fuente: elaboración propia.

\section{Conclusiones}

El análisis de los tres casos de estudio pone de manifiesto la omisión del espacio arquitectónico como un componente importante en el proceso de asistencia a las mujeres que sufren violencia de género. De hecho, en España los centros adquieren la categoría de alojamiento en su sentido más primario: un techo y una cama, sin que su programa haya variado desde los años 80 y 90 del siglo XX, con excepciones como la de la Casa Malva de Gijón. 
Se ha verificado la influencia de las cuatro cualidades arquitectónicas en el grado de hogaridad de los centros. Lograr un nivel satisfactorio, al menos en dos de ellas, permitiría aproximarse a la consideración de hogar. En cualquier caso, para que esas cualidades puedan reconocerse, los centros han de dotarse de una estructura organizativa adecuada a sus requerimientos.

La seguridad, por ejemplo, se haya condicionada por la inclusión de un local para la vigilancia y el control en el programa de necesidades. Una posible carencia que puede paliarse, sin embargo, mediante la consideración de alternativas aportadas por otros indicadores de esta misma cualidad

Otro tanto sucede con la convivencia, y la intimidad, que se ven favorecidas por distribuciones que incorporen espacios multifuncionales, flexibles y accesibles. Ambas cualidades se refuerzan a través de la legibilidad del espacio, y de un ajuar versátil, que permita a cada usuaria acomodarlo a su manera de habitar. Por otro lado, la consecución de una idónea protección acústica y visual depende de la organización espacial variada y diversa, y no solo del acondicionamiento constructivo.

Por su parte, la interacción ambiental en estos centros se encuentra condicionada por la percepción de seguridad, que requiere de filtros espaciales. Elementos que intermedien tanto entre el acceso desde la calle al edificio, como en la relación entre las estancias residenciales y el espacio público. A su vez, los espacios in-útiles, complemento de los útiles, contribuyen a dicha interacción, al inducir a la apropiación del espacio.

Otro aspecto del análisis realizado plantea la relación entre tipología edificatoria, hogaridad y modalidad del recurso. Una lectura superficial podría llevarnos a vincular hogaridad y unidades residenciales autónomas, sin otras alternativas. Sin embargo, las tres modalidades reseñadas, vivienda compartida, centro residencia, o centro integral pueden asimilarse a un hogar, siempre que el proyecto arquitectónico tenga en cuenta los indicadores, y defina inmuebles con una superficie suficiente, un programa de necesidades apropiado, y una organización versátil y flexible.

Por otro lado, el término centro de acogida encierra diferentes modalidades, cada una con un programa específico. Pero todas necesitan abordarse como tipos arquitectónicos propios, no siendo válida las tipologías residenciales comunes, de vivienda familiar o de residencia colectiva.

Pero el atento estudio de estos centros abre otras líneas de investigación. Una, referida a las condiciones urbanas del entorno; otra, al estudio en profundidad del programa de necesidades en función de la modalidad del recurso; y una tercera, centrada en el diseño de los espacios útiles e inútiles, privados y comunes. No cabe duda de que estas líneas son merecedoras de ser abordadas en sucesivos trabajos.

\section{Agradecimientos}

Agradecemos a la Oficina de Igualdad de la Universidade da Coruña y a la Secretaría Xeral de Igualdade de la Xunta de Galicia, la oportunidad de desarrollar el proyecto TIP-CAVI2, con el que se ha iniciado la línea de investigación sobre los Centros de Acogida para Víctimas de Violencia de Género desde la óptica arquitectónica. De igual modo, agradecemos a las y los revisores sus comentarios y sugerencias, que sin duda han contribuido en la profundidad del artículo.

\section{Autoría}

Los tres autores han contribuido en igual proporción en la toma de datos, elaboración de esquemas, revisión bibliográfica y edición del artículo.

ACE, 16 (46) CC BY-ND 3.0 ES | UPC Barcelona, España | Los centros de acogida para víctimas de violencia de género 
Conflicto de intereses: Los autores declaran que no hay conflicto de intereses.

\section{Bibliografía}

Arenal, C. (1883). "La mujer de su casa". En Caballé, A. (Prol.), Santolaya, A. (Il.) (2020). Concepción Arenal. La mujer del porvenir. La mujer de su casa (pp.129-218). Alcobendas, España: Nórdica libros.

Bachelard, G. (1998/1957). La poética del espacio. Madrid, España: Fondo de Cultura Económica de España.

Becerra Verdugo, L. (2017). Arquitectura como herramienta terapéutica en el campo de la salud mental. Nuevas configuraciones arquitectónicas para el paradigma actual de integración en psiquiatría (Tesis doctoral). Recuperado de: http://repositorio.uchile.cl/handle/2250/144264

Bennett, L.; Riger, S.; Schewe, P; Howard, A. y Wasco S. (2004). Effectiveness of Hotline, Advocacy, Counseling and Shelter Services for Victims of Domestic Violence. A Statewide Evaluation. Journal of Interpersonal Violence, 19(7), 815-829. Recuperado de https://pdfs.semanticscholar.org/1702/1da23f594453c8e2e072e0851ab46d376de4.pdf

Booth, Ch.; Darke, J.; Yeandle, S. (1998). La vida de las mujeres en las ciudades. Madrid, España: Narcea.

Bosch Fiol, E.; Ferrer Pérez, V. A. (2000). La violencia de género: De cuestión privada a problema social. Psychosocial Intervention, 9 (1), 7-19.

Browning, W.; Ryan, C. y Clancy, J. (2014). 14 Patterns of Biophilic Design. New York, EEUU: Terrapin Bright Green, LLC.

Cerasoli, M. (2010). Periferias urbanas degradadas. Transformación de los espacios y evolución del habitar. ¿Cómo intervenir? ACE: Architecture, City and Environment, 5(14), 45-66. DOI: http://dx.doi.org/10.5821/ace.v5i14.2505

Cañada Vicinay, J. A. (2007). Trabajo y familia frente trabajo o familia: conciliación o elección, el dilema de las jóvenes esposas. ACE: Arquitectura, Ciudad y Entorno, 2(5), 381-400. DOI: http://dx.doi.org/10.5821/ace.v2i5.2408

Carreiro, M. y López, C. (Eds.) (2016). La casa. Piezas, ensambles y estrategias. Málaga, España: Recolectores Urbanos.

Carreiro, M. y López, C. (Eds.) (2019). Entre-lugares. Las fronteras domésticas. Málaga, España: Recolectores urbanos.

Carreiro-Otero, M. et al. (2019). TIP-CAVI2: tipos e programas de centros de acollida para vítimas de violencia de xénero. Recuperado de http://hdl.handle.net/2183/25269

Consejo de las Mujeres de Bilbao por la Igualdad (2012). Mapa de la ciudad prohibida. Bilbao. Recuperado de: http://pdf.elcorreo.com/documentos/2012/mapa-ciudad-prohibida.pdf

Dobash, R. P. y Dobash, R. E. (1992). Women, violence \& social change. Londres, Inglaterra: Routledge.

ACE, 16 (46) CC BY-ND 3.0 ES | UPC Barcelona, España | Los centros de acogida para víctimas de violencia de género 
Donnelly, S. (2020). Design Guide for Refuge Accommodation for women and children. Brodway, Australia: UTS Shopfront. Recuperado de UTS-Refuge-Design-Guide Samantha-Donnelly 0.pdf (commonwealthsaysnomore.org)

Falcó Martí, R. (2003). Arqueología del género: espacios de mujeres, mujeres con espacio. Alicante, España: Centro de Estudios sobre la Mujer.

Ginzburg, N. (2017). A propósito de las mujeres. Madrid, España: Lumen.

Gray, A. (2019). Can Psychology Help Combat Anxiety in Crafting Welcoming Hospitality Spaces? Metrópolis. Recuperado de https://www.metropolismag.com/interiors/hospitalityinteriors/environmental-psychology-hospitality/

Instituto Asturiano de la Mujer (2020). La Casa Malva. Recuperado de https://iam.asturias.es/red-decasas-de-acogida-del-principado-de-asturias

Joshi, R. (2017). Understanding the Built Environment of Shelter Homes for Survivors of Domestic Violence. All Theses. 2642. Recuperado de https://tigerprints.clemson.edu/all theses/2642

La Torre, E. y Roig Fortaleza, A. (2011). Los recursos de acogida temporal para mujeres sobrevivientes a situaciones de violencia machista intrafamiliar. Crítica penal y poder, (1) 88-116. Recuperado de https://revistes.ub.edu/index.php/CriticaPenalPoder/article/view/1987

López Díaz, A. J. (2019). Introducción. En López Díaz, Ana Jesús (Ed.). Violencias de Género. Persistencias y nuevas formas (pp. 9-14). Madrid, España: Los Libros de La Catarata.

Lotito Catino, F. (2009). Arquitectura, psicología, espacio e individuo. AUS [Arquitectura / Urbanismo / Sustentabilidad], (6) 12-17. DOI: http://dx.doi.org/10.4206/aus.2009.n6-03

Merelas, T. (2017). Comezar desde cero: Voces de mulleres recuperando as súas vidas. Ferrol, España: Embroda.

Moriana Mateo, G. (2014). La protección de la exclusión social y la violencia de género. Humanismo y Trabajo Social, 13-14, 233-248. Recuperado de http://www4.unileon.es/trabajo social/revista.asp

Moriana Mateo, G. (2015). Barreras para escapar de la violencia de género: la mirada de las profesionales de los centros de protección de mujeres. Cuadernos de trabajo social, 28(I), 93-102. Recuperado de https://revistas.ucm.es/index.php/CUTS/issue/view/2759

Moriana Mateo, G. (2016). Los centros de acogida para mujeres que sufren violencia de género: ¿protección o control? En Escrig Gil, G.; Ortí Porcar, M.J. y Sales Boix, A. (Eds.). Seminario Internacional contra la Violencia de Género. Eliminar obstáculos para alcanzar la igualdad (pp. 177-186). Recuperado de: http://roderic.uv.es/bitstream/handle/10550/64660/Z.-PDF-Actas-seminario-internacional-VGversion-WEB3.pdf? sequence=1\&isAllowed $=y$

Pallasmaa, J. (1994). Identity, Intimacy and Domicile. Notes on the phenomenology of home. ARK. The Finnish Architectural Review, $1 . \quad$ Recuperado de http://www.uiah.fi/studies/history2/e ident.htm\#references 
Peña Cristiá, M. M. de la (2004). Mujeres Maltratadas. Casas de acogida en Galicia (Trabajo Fin de Máster). Universidad a Distancia de Madrid. Recuperado de http://pmayobre.webs.uvigo.es/master/textos/lola ferreiro/1mujeres maltratadas.doc

Pinilla, R. (2005). Vivienda, casa, hogar: las contribuciones de la filosofía al problema del habitar. Documentación social, 138, 13-40.

Pizzey, E. (15 de diciembre 2011). To say emotional abuse is as bad as violence insults every battered wife. Mail Online. Recuperado de http://www.dailymail.co.uk/debate/article-2074284/Domesticviolence-To-say-emotional-abuse-bad-insults-battered-wife.html

Portas Pérez, T. (2019). Violencia de género como crimen ontológico. En López Díaz, A. J. (ed.). Violencias de Género. Persistencias y nuevas formas, 17-28. Madrid, España: Los Libros de La Catarata.

Rasmussen, S. E. (1974/1965). Experiencia de la arquitectrasura. Barcelona, España: Labor.

Rebollo Sánchez, I. y Bravo Campanón, C. (2005). Casas de acogida: desde la experiencia a la reflexión. Cuadernos de trabajo social, 18, 317-332. Recuperado de Recuperado a partir de https://revistas.ucm.es/index.php/CUTS/article/view/CUTS0505110317A

Refuerzo B. J. y Verderber, S. (1993). In support of a new life: a shelter for victims of domestic violence. Journal of Architectural and Planning Research, 10(1): 40-58. Recuperado de https://www.jstor.org/stable/43029275

Romero Carrasco, A. E.; Brustad, R. J. y García Mas, A. (2007). Bienestar psicológico y su uso en la psicología del ejercicio, la actividad física y el deporte. Revista Iberoamericana de Psicología del Ejercicio $\quad y \quad$ el Deporte, 2(2), 31-52. $\quad$ Recuperado de https://www.redalyc.org/articulo.oa?id=3111/311126258003

Ruíz Sánchez, J. (2011). ¿Qué ciudad...? Acerca de la necesidad de reformular la pregunta. Feminismo/s, 17, 23-43.

Ruffa, B. (1990). Mujeres maltratadas: casas refugio y sus alternativas. Texas, EEUU: Sendas.

Ryff, C. D. (1989). Happiness is everything, or is it? Explorations on the meaning of psychological wellbeing. Journal of personality and social psychology,57(6), 1069-1081. DOI: https://doi.org/10.1037/0022-3514.57.6.1069

Ryff, C. D. (1995). Psychological Well-Being in Adult Life. Current Directions in Psychological Science, 4(4), 99-104. Recuperado de: http://www.jstor.org/stable/20182342?origin=JSTOR-pdf

Ryff, C. D. (2017). Eudaimonic well-being, inequality, and health: Recent findings and future directions. International review of economics, 64(2), 159-178.

Sánchez de Madariaga, I. (2004). Infraestructuras para la vida cotidiana y calidad de vida. Ciudades, 8. DOI: https://doi.org/10.24197/ciudades.08.2004.101-133

Sánchez de Madariaga, I. (2009). Vivienda, movilidad y urbanismo para la igualdad en la diversidad: ciudades, género y dependencia. Ciudad y territorio. Estudios Territoriales, XLI (161-162), 581-598. Recuperado de https://recyt.fecyt.es/index.php/CyTET/article/view/75953

ACE, 16 (46) CC BY-ND 3.0 ES | UPC Barcelona, España | Los centros de acogida para víctimas de violencia de género 
Seguí, J. (2006). Arquitectura y narración. // Jornadas sobre Investigación en Arquitectura y Urbanismo 21, 22, 23 de septiembre (138). Sant Cugat del Vallès, Barcelona, España: ETSA.

Senosiain, J. (1998). Bioarquitectura en busca de un buen espacio. México D.F., México: Limusa.

Simancas Yovane, K. (2003). Reacondicionamiento bioclimático de viviendas de segunda residencia en clima mediterráneo (Tesis doctoral). Recuperado de http://hdl.handle.net/2117/93425,

Smithson, A. (1974). How to recognize and read mat-building: mainstream architecture as it has developed towards the mat-building. Architectural Design, 9, 573. Reeditado por Sarkis, H. (2001). Case: Le Corbusier's Venice Hospital and the matbuilding revival. Munich, Alemania: Prestel Verlag.

Sullivan, C. M., y Gillum, T. (2001). Shelters and Other Community-Based Services for Battered Women and Their Children. En Rencetti, C. M.; Edlson, J. L. y Bergen, R. K. (Eds.) Sourcebook on violence against women. Thousand Oaks, California, EEUU: Sage Publications, 247-260. Recuperado de https://cap.vaw.msu.edu/wp-content/uploads/2014/05/chapter13.pdf.

Tester, G., y Harvey Wingfield, A. (2013). Moving Past Picket Fences: The Meaning of "Home" for Public Housing Residents. Sociological Forum, 28(1), 70-84. Recuperado de https://www.jstor.org/stable/23362175?seq=1\&cid=pdf-reference

Ugarte-Fidalgo, S. et al. (2019). Unidades residenciales en los Centros de Acogida para Víctimas de Violencia de Género. En López Díaz, A. J. (ed.). Violencias de Género. Persistencias y nuevas formas (pp. 96-110). Madrid, España: Los Libros de La Catarata.

Valera, S. (1999). Espacio privado, espacio público: Dialécticas urbanas y construcción de significados. Tres al cuarto, 6, 22-24. Recuperado de http://www.ub.edu/escult/editions/Otresal.pdf

Wagenaar, M. (2008). Van huis en haard. Betekenis van architektuur in de zorg voor mishandelde vrouwen en hun kinderen. Bussum, Netherlands: Uitgeverij THOTH.

Wathen, C. N.; Harris, R. M.; Ford-Gilboe, M. y Hansen, M. (2015). What Counts? A Mixed-Methods Study to Inform Evaluation of Shelters for Abused Women. Violence against Women, 21(1), 125-146. DOI: https://doi.org/10.1177/1077801214564077

Woolf, V. (2004/1929). Un cuarto propio. Madrid, España: Alianza Editorial.

ACE, 16 (46) CC BY-ND 3.0 ES | UPC Barcelona, España | Los centros de acogida para víctimas de violencia de género 